\title{
The microbial nitrogen-cycling network
}

2

Marcel M.M. Kuypers, Hannah K. Marchant \& Boran Kartal

Max Planck Institute for Marine Microbiology, Bremen, Germany

Correspondence to M.M.M.K. mkuypers@mpi-bremen.de

Abstract I Nitrogen is an essential component of all living organisms and the main nutrient limiting life on our planet. By far the largest inventory of freely accessible nitrogen is atmospheric dinitrogen, but most organisms rely on more bioavailable forms of nitrogen, such as ammonium and nitrate, for growth. The availability of these substrates depends on diverse nitrogen transforming reactions that are carried out by complex networks of metabolically versatile microorganisms. In this Review, we summarize our current understanding of the microbial nitrogen-cycling network including novel processes, their underlying biochemical pathways, the involved microorganisms, their environmental importance and industrial applications.

\section{Introduction}

Nitrogen is an essential element for all living organisms and is required for the biosynthesis of key cellular components such as proteins and nucleic acids. Atmospheric dinitrogen gas is the largest inventory of freely accessible nitrogen and it is biologically available to highly diverse but rare nitrogen-fixing bacteria and archaea. Other organisms must rely for growth on more reactive forms of nitrogen, such as ammonium and nitrate. This bioavailable nitrogen is rare in many environments, and the availability of this growth-limiting nutrient is controlled primarily by microbial reactions that alter the oxidation state of nitrogen.

Human activity has had a profound effect on the amount of bioavailable nitrogen, mainly due to the high input of industrial nitrogen-based fertilizers ${ }^{1}$. Food production for about $50 \%$ of the human population currently relies on industrial fertilizers ${ }^{2}$. This fertilizer use and legume cultivation has nearly doubled the nitrogen input to terrestrial and marine ecosystems ${ }^{1}$. To predict the consequences of this input, there is a pressing need to understand the basic mechanisms that underlie microbial nitrogen transformations.

Microorganisms can transform nitrogen compounds as reactive and toxic as nitric oxide or as inert as dinitrogen gas. Microbial transformations of nitrogen are often depicted as a cycle 
consisting of six distinct processes that proceed in an orderly fashion. This view of the nitrogen cycle implies that a molecule of dinitrogen gas is first 'fixed' to ammonia, which is 'assimilated' into organic nitrogen (that is, biomass). The degradation of organic nitrogen, 'ammonification', releases a molecule of ammonia, which is subsequently oxidized to nitrate through 'nitrification' $\left(\mathrm{NH}_{4}{ }^{+} \rightarrow \mathrm{NO}_{2}{ }^{-} \rightarrow \mathrm{NO}_{3}{ }^{-}\right)$and eventually converted back to a molecule of dinitrogen gas through 'denitrification' $\left(\mathrm{NO}_{3} \rightarrow \mathrm{NO}_{2} \rightarrow \mathrm{NO} \rightarrow \mathrm{N}_{2} \mathrm{O} \rightarrow \mathrm{N}_{2}\right)$ or 'anaerobic ammonium oxidation' (anammox; $\mathrm{NO}_{2}^{-}+\mathrm{NH}_{4}^{+} \rightarrow \mathrm{N}_{2}$ ). In reality, there is not one balanced nitrogen cycle. Instead, the six distinct processes are associated with nitrogen fluxes of vastly different magnitude (Box 1).

Nitrogen-transforming microorganisms are generally classified according to one of the six processes they are involved in: 'nitrifiers' carry out nitrification, 'denitrifiers' denitrification, ' $\mathrm{N}_{2}$-fixers' nitrogen fixation, etc. However, genomic data collected during the last decade challenges this classification, as it has revealed tremendous metabolic versatility within nitrogen-transforming microorganisms. We now know that diverse microorganisms can fix dinitrogen gas and denitrify simultaneously ${ }^{3,4}$, and organisms classified as nitrite oxidizers can also grow on formate, hydrogen and sulfide ${ }^{5,6}$. Thus, due to their metabolic versatility, it has become nearly impossible to objectively classify nitrogen-transforming microorganisms according to the six classical processes (Box 1). We will use process names, such as denitrification and nitrification, but refrain from classifying organisms accordingly. This Review will focus on the redox reactions that convert nitrogen compounds, biochemical pathways, and the responsible enzymes (Fig. 1) and microorganisms.

Based on our current understanding, microorganisms can convert nitrogen compounds spanning redox states [G] from -3 to +5 using fourteen discrete redox reactions (Fig. 1). There is no change in redox state in the interconversion of organic nitrogen to ammonia. Nitrogenconverting enzymes are often found in very diverse microorganisms (see below). Many of these enzymes have only recently been identified. Four new reactions were discovered in the last decade: hydroxylamine oxidation to nitric oxide ${ }^{7,8}$ (Fig. 1; reaction 7), nitric oxide dismutation to dinitrogen gas and oxygen ${ }^{9}(9)$, hydrazine synthesis ${ }^{10}(12)$, and hydrazine oxidation to dinitrogen gas $^{10}(13)$. In addition, many new metabolic capabilities were discovered, such as phototrophic nitrite oxidation ${ }^{11}$ and complete ammonia oxidation to nitrate (comammox) $)^{12,13}$, and novel microorganisms such as ammonia-oxidizing archaea ${ }^{14}$, denitrifying eukaryotic foraminifera ${ }^{15}$ and symbiotic heterotrophic nitrogen-fixing cyanobacteria ${ }^{16}$ were identified.

In this Review, we present these new findings in the context of our current understanding of microbial transformations of nitrogen. We describe microbial nitrogen-transforming reactions, 
microorganisms and their physiological and environmental function, and present reactions that are likely to exist, but have not yet been discovered. Furthermore, we will discuss the complex network of interactions between nitrogen-transforming microorganisms and its impact on global biogeochemical nitrogen cycling.

\section{Nitrogen-transforming reactions}

\section{Nitrogen fixation.}

Atmospheric dinitrogen gas is the largest reservoir of freely accessible nitrogen, but it is biologically available only to microorganisms that carry the nitrogenase metalloenzyme and thus can fix dinitrogen into ammonia. Nitrogenase is widespread in bacteria and archaea and provides them with a competitive advantage in environments that are depleted in bioavailable nitrogen. There are three different types of nitrogenase - iron-iron (FeFe), vanadium-iron $(\mathrm{VFe})$ and molybdenum-iron $(\mathrm{MoFe})$ nitrogenases ${ }^{17}$. They have similar sequence, structural and functional properties, but vary in their metal cofactor. All nitrogenases are composed of two components (Fig 2a). anfDGK, vnfDGK or nifDK encode the catalytic component of nitrogenases that have iron, vanadium or molybdenum in the active center, respectively ${ }^{17,18}$. In addition, anfH, vnfH or nifH encode ironcontaining electron transfer proteins (known as nitrogenase reductase or iron protein. $\mathrm{NifH}$ is used as a gene marker for the detection of nitrogen-fixing microorganisms in the environment ${ }^{18}$. The soil bacterium Azotobacter vinelandii encodes all three types of nitrogenases, whereas other microorganisms such as the marine nitrogen-fixers Trichodesmium spp. only have MoFe nitrogenase ${ }^{18}$. Whereas vanadium is seldom limiting, molybdenum and iron are rare in the terrestrial and marine environment, respectively, and can therefore limit nitrogen fixation in these ecosystems ${ }^{19}$.

During nitrogen fixation, an electron carrier such as ferredoxin first reduces the iron protein, which subsequently reduces the catalytic component. This requires the iron and catalytic proteins to dissociate and reassociate ${ }^{20}$. Per molecule of $\mathrm{N}_{2}$ fixed 16 molecules of adenosine triphosphate are consumed ${ }^{20}$. Additional bioenergetic costs arise from the production of powerful reductants [G] such as ferredoxin, and the protection of the oxygen-labile nitrogenase $\mathrm{e}^{21}$. Because oxygen exposure deactivates nitrogenases, oxygenic phototrophic [G] cyanobacteria, such as Trichodesmium spp., Crocosphaera watsonii, and Nodularia spp., often separate $\mathrm{N}_{2}$ fixation from photosynthesis, either spatially (for example in heterocysts, which are specialized $\mathrm{N}_{2}$-fixing cells) or temporally ${ }^{22}$. Even non-photosynthetic organisms living in oxic environments require mechanisms, such as enhanced oxygen respiration, 3 detoxification via 
103 superoxide dismutase and conformational changes of nitrogenase, to protect their nitrogenase

104 from oxygen ${ }^{23}$. The existence of a completely different, oxygen-insensitive pathway of $\mathrm{N}_{2}$

105 fixation using an 'unusual nitrogenase' was recently refuted ${ }^{24}$.

106 Although no $\mathrm{N}_{2}$-fixing eukaryotes have been found, many nitrogen-fixing microorganisms live 107 in symbioses with eukaryotes. The unicellular cyanobacterium Candidatus 108 Atelocyanobacterium thalassa (UCYN-A), which lives in symbiosis with small unicellular 109 haptophyte algae such as Braarudosphaera bigelowii, is one of the most widespread nitrogen110 fixing microorganisms and has a key role in marine nitrogen fixation ${ }^{16,25}$. Symbiotic nitrogen111 fixing microorganisms are also part of the gut microbiota of animals such as termites and can 112 be found in special bacteriocytes [G] in bivalves ${ }^{26,27}$. Moreover, nitrogen-fixing members of 113 the Rhizobiales order live in special root nodules of crop legumes, such as alfalfa, beans, peas 114 and soy, which provide $20 \%$ of food protein worldwide (Fig. 3c.) ${ }^{28}$.

\section{Ammonia oxidation to hydroxylamine.}

117 All known aerobic ammonia-oxidizing bacteria and archaea activate ammonia by oxidizing it 118 to hydroxylamine using ammonia monooxygenase (AMO) ${ }^{29}$. Most ammonia-oxidizing bacteria 119 belong to the Betaproteobacteria and Gammaproteobacteria classes and are 120 chemolithoautotrophs that oxidize ammonia to nitrite ${ }^{30}$. They can be found in nearly all 121 environments, including fertilized soils ${ }^{31}$ and wastewater treatment plants. Archaea belonging 122 to the Thaumarchaeota [G] phylum such as Nitrosopumilus maritimus can also grow chemolithoautotrophically by oxidizing ammonia to nitrite ${ }^{14}$. Their discovery resolved the longstanding mystery of the apparently rare ammonia oxidizers in the oceans ${ }^{32,33}$. Thaumarchaeota are more abundant than bacteria in some sandy and silty clay soils ${ }^{31,34}$. Furthermore, the isolation of the acidophilic [G] ammonia-oxidizing archaeon Candidatus Nitrosotalea

127 devanaterra overturned the common assumption that chemolithoautotrophic ammonia oxidation could not occur at low $\mathrm{pH}$ because of low ammonia availability ${ }^{35}$. Many ammonia oxidizers, such as Nitrosospira sp. and Nitrososphaera viennensis, can also degrade organic nitrogen compounds, for example by hydrolyzing urea with ureases, to produce additional 131 ammonia ${ }^{36,37}$. The archaeon Nitrososphaera gargensis can also produce ammonia by 132 hydrolyzing cyanate with a cyanase ${ }^{38}$.

133 Recently, the ability to oxidize ammonia has also been found in members of the genus 134 Nitrospira, which were previously assumed to only be capable of nitrite oxidation ${ }^{12,13}$. The 135 discovery of these bacteria that oxidize ammonia to nitrate (complete ammonia oxidation 136 (comammox)), refuted the dogma that the oxidation of ammonia and nitrite requires two distinct 
groups of microorganisms. The bacteria that perform the comammox process such as Nitrospira

138 inopinata appear well adapted to ammonia-limited environments and can outcompete most cultured ammonia oxidizing microorganisms for ammonia ${ }^{39} .2$ The transient accumulation of nitrite in comammox cultures grown on ammonia indicates that they more efficiently oxidize ammonia than nitrite ${ }^{12,13,39}$. We hypothesize that bacteria that perform the comammox process would oxidize ammonia to nitrate under ammonia-limited conditions and perform partial ammonia oxidation to nitrite under oxygen-limited conditions.

AMO is closely related to methane monooxygenase (MMO), which is found in methanotrophs [G] such as gammaproteobacteria ${ }^{40}$ and $\mathrm{NC}-10^{9}$ [G]. MMO can also oxidize ammonia to hydroxylamine, although very inefficiently (Fig. 1) ${ }^{41}$. Similarly, AMO can also oxidize methane, but less efficiently than $\mathrm{MMO}^{30}$. Intriguingly, amo sequences of bacteria that perform the comammox process were detected in the environment (for example in groundwater) already before their discovery, but were wrongly assigned as particulate methane monooxygenase (pmo) genes of the filamentous methane-oxidizing Crenothrix polyspora ${ }^{42}$. Recent resequencing of $C$. polyspora and other Crenothrix species revealed that they actually contain typical gammaproteobacterial pmo and not $a m o^{43}$.

\section{Hydroxylamine oxidation to nitric oxide and further to nitrite.}

155 Aerobic oxidation of ammonia to hydroxylamine is an endergonic [G] reaction. Therefore, all 156 aerobic ammonia oxidizers conserve energy by further oxidizing hydroxylamine. It was 157 believed that aerobic ammonia-oxidizing bacteria oxidize hydroxylamine to nitrite using octaheme hydroxylamine oxidoreductase (HAO). Recently, it was shown that the product of

159 HAO is not nitrite but nitric oxide, which is further oxidized to nitrite by an unknown enzyme ${ }^{7}$.

160 Although the enzyme catalyzing the latter reaction has not been conclusively identified, copper-

161 containing nitrite reductase (Cu-NIR) working in reverse has been suggested to catalyze it ${ }^{7}$. All 162 ammonia-oxidizing bacteria, including the newly discovered Nitrospira spp., which can oxidize 163 ammonia all the way to nitrate, contain $\mathrm{AMO}$ and $\mathrm{HAO}^{12,13}$. By contrast, known ammonia164 oxidizing archaea do not encode $\mathrm{HAO}$ and the archaeal enzyme responsible for hydroxylamine oxidation remains unknown ${ }^{44,45}$.

166 HAO belongs to a family of octaheme proteins (Fig. 2b) found in diverse microorganisms ${ }^{44,46}$.

167 The genomes of anaerobic ammonium-oxidizing bacteria encode $\sim 10 \mathrm{HAO}$-like proteins ${ }^{46}$, and 168 one of these also oxidizes hydroxylamine to nitric oxide ${ }^{8}$. In anaerobic ammonium-oxidizing 169 bacteria this hydroxylamine oxidase (HOX) recycles hydroxylamine, which leaks from 170 hydrazine synthase (see below). 
171 Methane-oxidizing bacteria also produce hydroxylamine as a result of their unspecific ammonia 172 oxidation activity $^{30}$ (see above) and diverse methanotrophs in the Proteobacteria, 173 Verrucomicrobia [G], and NC10 phyla (for example, Candidatus Methylomirabilis oxyfera), 174 encode HAO-like proteins that likely oxidize hydroxylamine to nitric oxide, which is further 175 oxidized to nitrite or reduced to nitrous oxide ${ }^{8,47,48}$. Currently, it is unknown whether this

176 reaction directly contributes to energy conservation in methane-oxidizing bacteria.

Nitrite oxidation to nitrate.

179 Nitrite oxidation is the main biochemical pathway that produces nitrate, and is catalyzed by 180 nitrite oxidoreductase (NXR). NXR is encoded by aerobic nitrite-oxidizing bacteria (members 181 of the Alphaproteobacteria, Betaproteobacteria, Gammaproteobacteria, Chloroflexi, 182 Nitrospinae and Nitrospirae phyla) ${ }^{6}$, anoxygenic phototrophs [G] (for example, Thiocapsa sp. 183 strain KS1 and Rhodopseudomonas sp. strain LQ17) ${ }^{11,49}$ and anaerobic ammonium-oxidizing 184 bacteria $^{50}$. Whereas aerobic nitrite oxidizing bacteria directly couple nitrite oxidation by NXR 185 to energy conservation, anaerobic nitrite-oxidizing bacteria do not. Thiocapsa sp. Strain KS1 186 and Rhodopseudomonas sp. strain LQ17 can oxidize nitrite anaerobically by coupling it directly 187 to phototrophy ${ }^{11,49}$. Further, anaerobic ammonium-oxidizing bacteria might couple anaerobic 188 nitrite oxidation to carbon fixation ${ }^{51}$.

189 Nitrite-oxidizing bacteria are metabolically versatile and can grow on other substrates than 190 nitrite $^{6}$. Indeed, the comammox Nitrospira species oxidize ammonia to nitrate ${ }^{12,13}$. Nitrospira 191 moscoviensis grows aerobically on hydrogen and anaerobically on organic acids while respiring 192 nitrate ${ }^{52,53}$. Nitrate reduction in these nitrite-oxidizing bacteria is also catalyzed by NXR, which 193 is related to bacterial and archaeal nitrate reductases ${ }^{54}$.

194 The concerted activity of nitrite and ammonia oxidizing microorganisms in agricultural soils 195 converts N-based fertilizers to nitrate and has a key role in the loss of fertilizers to river and 196 ground waters leading to the eutrophication [G] of rivers, lakes and coastal waters. The same 197 two processes are also used in wastewater treatment plants as the first step of conventional 198 nitrogen removal (Box 2). In marine environments, nitrite-oxidizing bacteria generate nitrate, 199 the dominant form of biologically available nitrogen in the ocean, and contribute to carbon 200 fixation $^{55}$.

202 [H3] Nitrate reduction to nitrite.

203 Nitrate reduction to nitrite is used for respiration, known as dissimilatory nitrate reduction, and 204 for nitrogen assimilation into biomass. Dissimilatory nitrate reduction to nitrite can be carried 
out by microorganisms from all three domains of life. These microorganisms occur in all anoxic environments in which nitrate is present, including soils ${ }^{56}$, oxygen minimum zones ${ }^{57}$, marine sediments $^{58}$ and the human gastrointestinal system ${ }^{59}$. The reaction is catalyzed by either a membrane-bound (NAR) or a periplasmic (NAP) nitrate reductase ${ }^{60}$. Many organisms, including the model organism Paracoccus denitrificans, contain both NAP and NAR ${ }^{60}$. Nitrate reduction by NAR occurs in the cytoplasm and releases protons to the periplasm (Fig 2c), and thereby directly contributes to energy conservation through the proton motive force [G]. By contrast, NAP reduces nitrate to nitrite in the periplasm, and thus does not translocate protons required to create proton motive force ${ }^{60}$.

214 Dissimilatory nitrate reduction to nitrite is not merely the first step in denitrification. Some microorganisms such as the giant sulfur oxidizing Beggiatoa sp. $^{61}$, which is widespread in freshwater and marine sediments, reduce nitrate via nitrite to ammonium and many microorganisms such as some members of the ubiquitous marine clade SAR $11^{62}$ only reduce nitrate to nitrite (Fig. 1). Nitrate reduction is a major source of nitrite for other nitrogen-cycling processes including aerobic nitrite oxidation and anammox ${ }^{62-64}$. Dissimilatory nitrate reduction can be coupled to the oxidation of electron donors such as organic matter ${ }^{65}$, methane ${ }^{66,67}$ (for example, in Candidatus Methanoperedens spp.), sulfur compounds (for example, in Thiobacillus denitrificans ${ }^{68}$ ); $\mathrm{H}_{2}$ (for example, in Alcaligenes eutrophus) or iron (for example, Ferroglobus placidus ${ }^{69}$ ).

224 Nitrate is a major nitrogen source for eukaryotes, bacteria and archaea that contain assimilatory nitrate reductases (NAS) ${ }^{60}$. Considering that nitrate supports at least $20 \%$ of marine algal growth $^{70}$, nitrate assimilation likely exceeds the magnitude of most other redox driven nitrogencycle process in the ocean (Box 1). NAS, together with assimilatory nitrite reductases (see below), produces ammonia, which is incorporated into biomass ${ }^{60}$. Because NAS is located in the cytoplasm, nitrate assimilation requires nitrate transport into the cell by ATP-dependent transporters ${ }^{60}$. Due to this energy requirement, NAS expression is repressed in ammonia-replete environments, such as fertilized soils ${ }^{60}$.

Bacterial and archaeal NAS together with NAP, NAR and NXR belong to the dimethylsulfoxide reductase family, whereas eukaryotic assimilatory nitrate reductases belong to the sulfite oxidase family ${ }^{71}$. This suggests multiple origins of nitrate reductases. The distinction between assimilatory and dissimilatory nitrate reduction pathways is not absolute. In principle, nitrite produced by assimilatory nitrate reduction could be reduced further in the respiratory chain.

237 Conversely, Mycobacterium tuberculosis has been shown to use the NAR complex for nitrate assimilation $^{72}$. 


\section{Nitrite reduction to ammonium.}

241 Nitrite reduction to ammonium is used for both dissimilatory and assimilatory purposes.

242 Dissimilatory nitrite reduction to ammonium is carried out by most bacterial lineages, the 243 thermophilic Crenarcheota Pyrolobus fumarii ${ }^{73}$, methane-oxidizing archaea ${ }^{67}$, diatoms ${ }^{74}$ and 244 fungi ${ }^{75}$. This reaction is catalyzed by the periplasmic cytochrome c nitrite reductase (ccNIR) 245 encoded by $n r f A$, the octaheme nitrite reductase $(\mathrm{ONR})^{76}$ or the octaheme tetrathionate 246 reductase $(\mathrm{OTR})^{77}$. It is unclear whether the latter two enzymes are used for respiration or 247 detoxification of nitrite or hydroxylamine. Reduction of nitrite to ammonium involves the 248 formation of hydroxylamine as intermediate, which remains bound to the enzyme until it is 249 reduced to ammonium ${ }^{78}$.

250 Interestingly, the anaerobic ammonium-oxidizing bacterium $K$. stuttgartiensis can reduce nitrite 251 to ammonium, but lacks known ammonium-producing nitrite reductases. It is hypothesized that 252 nitrite reduction to ammonium instead might be accomplished by an HAO-like protein ${ }^{46}$. 253 Recently an HAO encoded by Epsilonproteobacteria ( $\varepsilon \mathrm{HAO})$, such as Campylobacter fetus and 254 Nautilia profundicola, was shown to reduce nitrite and hydroxylamine to ammonium, although 255 with poor efficiency ${ }^{79}$.

256 Dissimilatory nitrite reduction to ammonium is the key reaction in the so-called dissimilatory 257 nitrate reduction to ammonium (DNRA) process ${ }^{80}$. Microorganisms can grow using DNRA by 258 coupling it to the oxidation of electron donors, such as organic matter, $\mathrm{Fe}^{2+}, \mathrm{H}_{2}$, sulfide and 259 methane ${ }^{67,81-83}$. Little is known about the environmental importance of DNRA ${ }^{84,85}$; however, in 260 marine and lake sediments, DNRA appears to be favored over denitrification when there is an 261 excess of electron donor relative to nitrate ${ }^{58}$.

262 Assimilatory nitrite reductases produce ammonium and are as widespread as NAS, and both 263 types of enzymes are often encoded on the same nas operon ${ }^{54}$. The formation of primary nitrite 264 maxima [G] in the ocean has been attributed to the release of nitrite due to an uncoupling of assimilatory nitrate and nitrite reduction in phytoplankton ${ }^{86}$. The physiological reasons for this uncoupling are still unclear.

\section{Nitrite reduction to nitric oxide.}

269 Many microorganisms have the ability to reduce nitrite to nitric oxide, for example, 270 Proteobacteria, anaerobic ammonium-oxidizing bacteria, and Bacteroidetes ${ }^{54}$. These microorganisms are found in many environments, in which nitrate is available and oxygen concentrations are low, such as soils ${ }^{56}$, oxygen minimum zones $^{57}$ and marine sediments ${ }^{58}$. This 
reaction can be catalyzed by two unrelated enzymes: a heme-containing $\mathrm{cd}_{1}$ nitrite reductase

$274\left(\mathrm{~cd}_{1} \mathrm{NIR}\right.$ encoded by nirS) or a Cu-containing nitrite reductase (CuNIR encoded by nirK), which 275 are widespread among bacteria and archaea ${ }^{87}$. Both enzymes are located in the periplasm and 276 do not contribute directly to energy conservation ${ }^{54,65}$. These two enzymes also occur together 277 in a single microorganism, for example in Rhodothermus marinus ${ }^{87}$.

278 Commonly, nirS and nirK are used in environmental studies as gene markers for 'denitrifiers', 279 however, these genes are present in many other microorganisms, including anaerobic 280 ammonium-oxidizing bacteria, nitrite and methane-oxidizing bacteria and ammonia-oxidizing 281 bacteria and archaea ${ }^{88}$. Apart from CuNIR and $\mathrm{cd}_{1} \mathrm{NIR}$, other nitrite-reducing enzymes might exist; for example, some anaerobic ammonium-oxidizing bacteria contain neither of them, but can reduce nitrite to nitric oxide ${ }^{89}$. To carry out this reaction, these bacteria might use an HAOlike octaheme oxidoreductase ${ }^{46}$.

\section{Nitric oxide reduction to nitrous oxide or dinitrogen gas.}

287 Nitric oxide is a signaling molecule, a toxin ${ }^{90}$ and an intermediate of the denitrification, nitrification and anammox processes. Additionally, bacteria that perform oxygenic denitrification dismutate two molecules of nitric oxide to one molecule of dinitrogen gas and one molecule of oxygen ${ }^{9}$. Therefore, microorganisms capable of nitric oxide reduction can be found in a wide range of environments, including wastewater treatment plants ${ }^{46}$, agricultural soils $^{56,91}$, marine sediments ${ }^{58}$ and marine oxygen minimum zones ${ }^{57}$. Microbial nitric oxide reduction (Fig. 1) is the main source of nitrous oxide, a powerful greenhouse gas (310 times more potent than $\mathrm{CO}_{2}$ ) and the dominant ozone-depleting agent ${ }^{92}$. Nitrous oxide-producing nitric oxide reductases (NOR) are used for detoxification or respiration of nitric oxide, and belong to a diverse group of enzymes ranging from flavoproteins to heme copper oxidases, which are widespread throughout the tree of life. Flavo-diiron proteins, such as flavorubredoxin nitric oxide reductase (NORvw), are used to detoxify nitric oxide, for example by the sulfatereducing bacterium Desulfovibrio gigas $^{93,94}$. Other NOR-type enzymes are the NADHdependent cytochrome $\mathrm{P}_{450} \mathrm{NOR}$ found in the mitochondria of fungi, such as Fusarium oxysporum $^{95}$, and the hybrid cluster protein HCP recently discovered in Escherichia coli $^{96}$.

The heme copper oxidase family contains terminal oxidases, the cytochrome c-dependent 303 cNOR, quinol-dependent qNOR and the copper-containing $\mathrm{Cu}_{\mathrm{A}} \mathrm{NOR}$, which all have a role in nitric oxide respiration ${ }^{97-99}$. Nitrous oxide is an intermediate of denitrification and NOR is present in microorganisms, such as P. denitrificans and Pseudomonas stutzeri ${ }^{65}$. Nitrous oxide can also be the end-product of denitrification in some microorganisms, such as Pseudomonas 
chlororaphis $^{65}$. Ammonia-oxidizing bacteria can produce nitrous oxide in a process termed

308 nitrifier-denitrifcation, in which NOR is used to reduce nitric oxide formed upon nitrite reduction ${ }^{30}$. In cultures of ammonia-oxidizing bacteria and bacteria capable of carrying out the comammox process, nitrous oxide can also be formed through abiotic reactions of the extracellular intermediates hydroxylamine and nitric oxide ${ }^{100}$. Additionally, ammonia-oxidizing bacteria can produce nitrous oxide through the NOR-catalyzed reduction of nitric oxide, which is produced during hydroxylamine oxidation ${ }^{7,30}$. Similar to ammonia-oxidizing bacteria, methanotrophic bacteria produce nitrous oxide through the NOR-catalyzed reduction of nitric oxide formed upon hydroxylamine-oxidation (see above) and nitrite reduction ${ }^{47,48}$. By contrast, nitrous oxide production in ammonia-oxidizing archaea might exclusively involve the abiotic reactions of the intermediates nitric oxide and hydroxylamine ${ }^{45}$.

318 The use of nitrogen-based fertilizers has drastically increased nitrous oxide emissions ${ }^{101}$. Due to the concerted activity of nitrogen-transforming microorganisms, 3 to $5 \%$ of the nitrogen used as agricultural fertilizer is converted into nitrous oxide ${ }^{102,103}$. Nitrogen-based fertilizers are increasingly used to grow crops for biofuel production, which represents a potential replacement for fossil fuels. Herein lies a dilemma - the more fertilizer is used to produce biofuels, the more nitrous oxide emissions increase. Therefore, the fertilizer use for biofuel production counteracts the reduction in greenhouse gas emissions that is achieved by reducing the use of fossil fuels ${ }^{103}$.

Nitric oxide dismutation [G] to dinitrogen and oxygen gas (Fig. 1) is a recently discovered nitrogen transforming reaction ${ }^{104}$. Microorganisms such as $\mathrm{Ca}$. Methylomirabilis oxyfera found in anoxic systems rich in methane and nitrate (for example in eutrophied lakes and wetlands) use this reaction to produce their own molecular oxygen from nitrite ${ }^{9}$. This enables $\mathrm{Ca}$. Methylomirabilis oxyfera to live in anoxic environments and to use the aerobic methane oxidation pathway ${ }^{9}$. The dismutation reaction might involve an unusual qNOR, tentatively called nitric oxide dismutase (NO-D) ${ }^{9}$. Nitric oxide dismutation might be more widespread than previously thought, as similar unusual qNOR sequences are present in other phyla, such as Gammaproteobacteria (for example, HdN1 strain) and Bacteroidetes (for example, Muricauda ruestringensis $)^{104}$.

\section{Nitrous oxide reduction to nitrogen gas.}

338 Microbial nitrous oxide reduction to nitrogen gas is the main sink of this powerful greenhouse gas. The only known enzyme that catalyzes this reaction is nitrous oxide reductase (NOS), which, due to its location in the periplasm, does not directly contribute to energy conservation 
341 through proton motive force ${ }^{105}$. Diverse bacteria, including members of the Proteobacteria,

342 Bacteroidetes and Chlorobi phyla, and archaea from the Crenarchaeota and Halobacteria ${ }^{106}$ 343 utilize NOS. The discovery of a slightly different NOS-encoding gene in Wolinella 344 succinogenes $^{107}$ revealed an overlooked diversity of NOS sequences in soils ${ }^{108}$. Intriguingly, 345 organisms encoding this NOS variant often have no other nitrogen-oxide reductases ${ }^{87,91,109 .}$

346 Some eukaryotes, the Foraminifera and Gromiida, also reduce nitrous oxide, but their 347 enzymatic machinery is unknown ${ }^{15,110}$.

348 For a long time, it was believed that NOS was more sensitive to oxygen, $\mathrm{pH}$ and sulfide than 349 other nitrogen-oxide reductases ${ }^{105}$. Based on that apparent sensitivity, environmental emissions 350 of nitrous oxide were fully attributed to inhibition of NOS in organisms that reduce nitrate all 351 the way to $\mathrm{N}_{2}$, the so-called 'complete denitrifiers'. Additionally, interactions of so-called 352 'incomplete denitrifiers', which are microorganisms that only perform, for example, nitrite 353 reduction to nitrous oxide or nitrous oxide reduction to dinitrogen gas, and their niche 354 differentiation might cause imbalances between nitrous oxide production and consumption in 355 many environments, such as soils and marine environments ${ }^{91,109,111}$.

\section{Hydrazine synthesis and hydrazine oxidation to dinitrogen gas.}

358 Until recently, it was generally believed that ammonium could only be activated with molecular 359 oxygen and that bioavailable nitrogen could only be lost as dinitrogen gas through 360 denitrification $^{112}$. The discovery of anaerobic ammonium oxidation (anammox) to dinitrogen 361 gas with nitrite as the terminal electron acceptor overturned both of these dogmas ${ }^{51,113,114}$. 362 Hydrazine synthase (HZS) is the only known enzyme that can activate ammonium 363 anaerobically ${ }^{89}$, and it is exclusively found in anaerobic ammonium-oxidizing bacteria that 364 belong to five genera in the phylum Planctomycetes ${ }^{89,115,116}$. HZS is also the only enzyme known 365 to form an $\mathrm{N}-\mathrm{N}$ bond from two discrete $\mathrm{N}$-compounds, producing hydrazine as a free 366 intermediate in a two-step reaction ${ }^{10,115}$. The hypothetical mechanism of hydrazine synthesis 367 starts with nitric oxide reduction to hydroxylamine (Fig 2d), which is subsequently 368 comproportionated [G] together with ammonium into hydrazine, one of the most potent 369 reductants in nature ${ }^{10,115}$. During this reaction, hydroxylamine is transfered from one active site 370 to the next (Fig. 2d), which might result in hydroxylamine-loss from HZS. Two of the genes 371 encoding HZS, $h z s A$ and $h z s B$, are used as genetic markers for anaerobic ammonium-oxidizing 372 bacteria in the environment ${ }^{117,118}$.

373 Hydrazine is oxidized to dinitrogen by hydrazine dehydrogenase (HDH) ${ }^{10,119}$. Based on amino 374 acid sequences, this enzyme is related to HOX and HAO; however, it is inhibited by 
375 hydroxylamine and can only oxidize hydrazine ${ }^{119}$. Hydrazine oxidation occurs in a unique 376 membrane-bound structure called the anammoxosome [G] and is most likely directly associated 377 with energy conservation ${ }^{46,120,121}$. Intriguingly, all catabolic enzymes of anaerobic ammonium378 oxidizing bacteria (HDH, HZS, NIR, HOX and NXR) are located exclusively in the 379 anammoxosome ${ }^{122}$.

$380 \mathrm{HDH}$ is responsible for the release of a substantial amount of dinitrogen to the ${ }^{119}$ In the last 381 decade, it became clear that the anammox process is a major nitrogen sink in the ocean ${ }^{123-125}$ 382 and it could also have an important role in terrestrial ecosystems ${ }^{126}$.

\section{Networks of nitrogen-transforming microorganisms}

There is an astonishing diversity of microorganisms that transform nitrogen and each of these microorganisms has discrete physiological requirements for optimal growth. As growth conditions in nature are highly variable and seldom optimal, nitrogen turnover by individual microorganisms is bound to be inefficient. However, nitrogen transformations in the environment are carried out by microbial communities that recycle nitrogen more efficiently than single microorganisms. Consequently, very little bioavailable nitrogen escapes to the atmosphere, and the small amount lost as dinitrogen gas is balanced by nitrogen fixation (Box 1). This apparent nitrogen homeostasis not only characterizes the global biosphere, but also many ecosystems, such as forest soils and ocean gyres $[\mathbf{G}]$. The microbial communities required to efficiently recycle nitrogen in these ecosystems are robust with respect to environmental changes and retain nitrogen-transforming reactions even when the species composition changes. The nitrogen-transforming reactions are linked by microorganisms that form complex networks in both natural and man-made ecosystems (Fig. 3).

400 The ocean gyres, the world's largest ecosystems, are nearly nitrogen-balanced due to extensive 401 nitrogen recycling (Fig. 3a). Here, the main nitrogen-transforming processes are nitrogen 402 assimilation by cyanobacteria, such as Prochlorococcus marinus ${ }^{70}$, ammonification by 403 mesozooplankton ${ }^{127}$ and heterotrophic bacteria, such as Pelagibacter ubique ${ }^{128}$ and nitrification 404 by Nitrosopumilus spp. and Nitrospina spp. (Fig. 3a; see also Box 1). Nitrogen fixation by 405 microorganisms, such as Trichodesmium spp. and UCYN-A (Atelocyanobacterium), is a rather 406 minor nitrogen-transforming process in the gyres ${ }^{70}$. Yet, due to the sheer extent of the area in 407 which nitrogen fixation occurs, it is the main supply of new bioavailable nitrogen to the ocean. 
In contrast to the ocean gyres, oxygen minimum zone waters cover less than $1 \%$ of the open ocean area, but might account for $30-50 \%$ of oceanic nitrogen $\operatorname{loss} 5^{57,70,125}$ (Box 1). Here, anaerobic microorganisms such Scalindua spp. co-occur with aerobic organisms such as

411 Nitrosopumilus spp. and Nitrospina spp. ${ }^{57}$. The microbial nitrogen-transforming network in 412 open ocean oxygen minimum zones is complex ${ }^{57}$ with all known nitrogen-converting processes 413 occurring alongside each other (Fig. 3b).

414 Similar to oxygen minimum zone waters, nitrogen-removing wastewater treatment plants are 415 characterized by imbalanced nitrogen-transformations. These man-made systems are designed 416 to convert ammonium to dinitrogen gas, which is lost to the atmosphere (Box 2).

417 Agricultural fields are among the largest man-made ecosystems and their microbial nitrogen418 transforming networks have been strongly affected by the anthropogenic input of nitrogen. The cultivation of legumes that form symbioses with nitrogen-fixing microorganisms have subsantially increased the nitrogen input to the environment ${ }^{2}$, ${ }^{129}$. Nitrogen-fixing microorganisms, such as Bradyrhizobium spp., often live in specialized root nodules and provide ammonium to the legumes (Fig. 3c). Ammonium that leaks out into the surrounding soil fuels other microbial nitrogen transformations, such as aerobic ammonia oxidation. In rice paddy fields, the use of industrial fertilizers has resulted in intense nitrification and enhanced nitrogen $\operatorname{loss}^{126}$. Recent studies reveal that these systems have highly complex nitrogentransforming networks, which include nitrite-reducing ( $\mathrm{Ca}$. Methylomirabilis spp.) and nitratereducing ( $\mathrm{Ca}$. Methanoperedens spp.) methanotrophs ${ }^{130}$ (Fig. 3d). In these ecosystems, some nitrogen-transforming microorganisms, such as anaerobic ammonium-oxidizing bacteria, can perform multiple redox reactions (reactions 1, 2, 5, 7, 10, 12, 13; Fig. 1). Still, processes such as nitrification and denitrification are performed by a complex network of specialists in a modular fashion (Fig. 3). Such modularity, which is a general feature of nitrogen-transforming microbial networks, results in cooperative and competitive interactions (examples in Fig. 3). A cooperative interaction exists between Nitrosopumilus spp. and Nitrospina spp. that together oxidize ammonia to nitrate (Figs. 3a, b). In most environments, nitrification is carried out by diverse assemblages of ammonia- and nitrite-oxidizing microorganisms, which also compete for ammonia and nitrite, respectively. Substrate competition also exists between microorganisms with very different metabolisms, such as Nitrospira spp., Ca. Methylomirabilis spp., Candidatus Brocadia spp., Ca. Methanoperedens spp. and Pseudomonas spp., which all compete for nitrite (Fig. 3d). Microbial interactions can also be simultaneously cooperative and competitive: Nitrosopumilus spp. produces nitrite for Scalindua spp., but both also compete for ammonia (Fig. 3b). 
442 The factors that control these interactions are poorly understood. Sometimes, a single 443 physiological characteristic is used to explain the dominance of certain nitrogen-transforming 444 microorganisms in the environment. For example, the abundance of ammonia oxidizing archaea 445 relative to bacteria in ammonia-depleted environments was attributed to the superior ammonia 446 affinity of the archaea ${ }^{31,131,132}$. Recently, however, it was shown that the terrestrial bacterium 447 Nitrospira inopinata, which performs the comammox process, has a higher ammonia affinity 448 than all cultured terrestrial ammonia-oxidizing $\operatorname{archaea}^{39}$. Yet, the microorganisms that perform 449 the comammox process do not dominate all ammonia-depleted terrestrial environments ${ }^{133}$. The 450 success of nitrogen-transforming microorganisms also depends on other factors, such as the use 451 of alternative substrates and cellular energy requirements. Such variables might have general 452 roles in shaping nitrogen-transforming microbial networks.

\section{Concluding remarks}

Identifying the factors that shape nitrogen-transforming networks will require greater insight into the physiology of the involved microorganisms and a deeper understanding of their ecology and evolution. Only a fraction of all microorganisms has been cultivated, and the uncultivated majority likely contains undiscovered metabolic pathways (Box 3). Cultivation, followed by painstaking biochemical, physiological and genomic characterisation has already changed our perspective of key nitrogen-cycle processes. Aerobic nitrite-oxidizing bacteria and anaerobic ammonium-oxidizing bacteria have a hitherto unexpected metabolic versatility that renders their classification as mere 'aerobic nitrite oxidizers' or 'anaerobic ammonia oxidizers' inadequate. Many aerobic nitrite oxidizers might grow as hydrogen-oxidizers, ammoniaoxidizers or nitrate reducers in the environment ${ }^{6}$. Anaerobic ammonium-oxidizing bacteria can also use short-chain fatty acids, methylamines and FeII as electron donors ${ }^{46,134}$ and they can use nitrate, MnIV and FeIII as electron acceptors ${ }^{46,135,136}$.

468 On the other hand, there is a growing realization that complete denitrification by single microorganisms is the exception rather than the rule, with many microorganisms being specialists that perform only one or a few nitrogen-oxide reduction reactions ${ }^{3,91,137}$. Specialized

471 nitrogen-oxide reducers often lack known genes enabling them to reduce nitrate all the way to $472 \mathrm{~N}_{2}{ }^{87,}{ }^{138}$. These specialist nitrogen-oxide reducers are often described as incomplete 473 denitrifiers', which is comparable to describing ammonia oxidizers such as Nitrosomonas spp. 474 as 'incomplete nitrifiers'. 
Undoubtedly, it will become increasingly difficult to classify organisms according to the classical six nitrogen-cycling processes, leaving it up to the eye of the beholder to define the function of an organism. If we can learn one thing from the last few decades of research, it is that microorganisms do not conform to boundaries. They will do whatever necessary in the perpetual struggle to survive.

1. Galloway, J.N. et al. Transformation of the Nitrogen Cycle: Recent Trends, Questions, and Potential Solutions. Science 320, 889-892 (2008). A comprehensive overview of the human impact on biogeochemical nitrogen cycling.

2. Erisman, J.W., Sutton, M.A., Galloway, J., Klimont, Z. \& Winiwarter, W. How a century of ammonia synthesis changed the world. Nature Geosci 1, 636-639 (2008).

3. Stein, L.Y. \& Klotz, M.G. The nitrogen cycle. Current Biology 26, R94-R98 (2016).

4. Yan, Y. et al. Nitrogen fixation island and rhizosphere competence traits in the genome of root-associated Pseudomonas stutzeri A1501. Proceedings of the National Academy of Sciences 105, 7564-7569 (2008).

5. Füssel, J. et al. Adaptability as the key to success for the ubiquitous marine nitrite oxidizer Nitrococcus. Science Advances 3, e1700807 (2017).

6. Daims, H., Lücker, S. \& Wagner, M. A New Perspective on Microbes Formerly Known as Nitrite-Oxidizing Bacteria. Trends in microbiology 24, 699-712 (2016).

7. Caranto, J.D. \& Lancaster, K.M. Nitric oxide is an obligate bacterial nitrification intermediate produced by hydroxylamine oxidoreductase. Proceedings of the National Academy of Sciences 114, 8217-8222 (2017).

8. Maalcke, W.J. et al. Structural basis of biological NO generation by octaheme oxidoreductases. Journal of Biological Chemistry 289, 1228-1242 (2014).

9. Ettwig, K.F. et al. Nitrite-driven anaerobic methane oxidation by oxygenic bacteria. Nature 464, 543-548 (2010). The discovery of oxygenic denitrification.

10. Kartal, B. et al. Molecular mechanism of anaerobic ammonium oxidation. Nature 479, 127-130 (2011). Isolation and characterization of the unique enzyme that produces free hydrazine.

11. Griffin, B.M., Schott, J. \& Schink, B. Nitrite, an electron donor for anoxygenic photosynthesis. Science 316, 1870-1870 (2007). The discovery of phototrophic nitrite oxidation.

12. Daims, H. et al. Complete nitrification by Nitrospira bacteria. Nature 528, 504509 (2015). The discovery of complete nitrification by a single microorganism.

13. van Kessel, M.A. et al. Complete nitrification by a single microorganism. Nature 528, 555-559 (2015). The discovery of complete nitrification by a single microorganism.

14. Konneke, M. et al. Isolation of an autotrophic ammonia-oxidizing marine archaeon. Nature 437, 543-546 (2005). The discovery of ammonia-oxidzing archaea.

15. Risgaard-Petersen, N. et al. Evidence for complete denitrification in a benthic foraminifer. Nature 443, 93-96 (2006).

16. Thompson, A.W. et al. Unicellular cyanobacterium symbiotic with a single-celled eukaryotic alga. Science 337, 1546-1550 (2012). Shows that the ubiquitous unicellular cyanobacterium UCYN-A forms a nitrogen fixing symbiosis with an algae. 
17. Eady, R.R. Structure-Function Relationships of Alternative Nitrogenases. Chemical Reviews 96, 3013-3030 (1996).

18. Zehr, J.P., Jenkins, B.D., Short, S.M. \& Steward, G.F. Nitrogenase gene diversity and microbial community structure: a cross-system comparison. Environmental Microbiology 5, 539-554 (2003).

19. Vitousek, P.M. \& Howarth, R.W. Nitrogen limitation on land and in the sea: How can it occur? Biogeochemistry 13, 87-115 (1991).

20. Bothe, H., Schmitz, O., Yates, M.G. \& Newton, W.E. Nitrogen Fixation and Hydrogen Metabolism in Cyanobacteria. Microbiology and molecular biology reviews : MMBR 74, 529-551 (2010).

21. Robson, R.L. \& Postgate, J.R. Oxygen and hydrogen in biological nitrogen fixation. Annual Reviews in Microbiology 34, 183-207 (1980).

22. Berman-Frank, I., Lundgren, P.\& Falkowski, P. Nitrogen fixation and photosynthetic oxygen evolution in cyanobacteria. Research in Microbiology 154, 157-164 (2003).

23. Inomura, K., Bragg, J.\& Follows, M.J. A quantitative analysis of the direct and indirect costs of nitrogen fixation: a model based on Azotobacter vinelandii. The ISME Journal 11, 166-175 (2017).

24. MacKellar, D. et al. Streptomyces thermoautotrophicus does not fix nitrogen. Scientific reports 6 (2016).

25. Martinez-Perez, C. et al. The small unicellular diazotrophic symbiont, UCYN-A, is a key player in the marine nitrogen cycle. Nature Microbiology 1, 16163 (2016).

26. Brune, A. Symbiotic digestion of lignocellulose in termite guts. Nature Reviews Microbiology 12, 168-180 (2014).

27. Lechene, C.P., Luyten, Y., McMahon, G. \& Distel, D.L. Quantitative imaging of nitrogen fixation by individual bacteria within animal cells. Science 317, 1563-1566 (2007).

28. Burris, R.H. \& Roberts, G. Biological nitrogen fixation. Annual review of nutrition 13, 317-335 (1993).

29. Hooper, A.B., Vannelli, T., Bergmann, D.J. \& Arciero, D.M. Enzymology of the oxidation of ammonia to nitrite by bacteria. Antonie van Leeuwenhoek 71, 59-67 (1997).

30. Arp, D.J. \& Stein, L.Y. Metabolism of inorganic N compounds by ammonia-oxidizing bacteria. Critical reviews in biochemistry and molecular biology 38, 471-495 (2003).

31. Prosser, J.I. \& Nicol, G.W. Relative contributions of archaea and bacteria to aerobic ammonia oxidation in the environment. Environmental Microbiology 10, 2931-2941 (2008).

32. Wuchter, C. et al. Archaeal nitrification in the ocean. Proceedings of the National Academy of Sciences 103, 12317-12322 (2006).

33. Francis, C.A., Roberts, K.J., Beman, J.M., Santoro, A.E. \& Oakley, B.B. Ubiquity and diversity of ammonia-oxidizing archaea in water columns and sediments of the ocean. Proceedings of the National Academy of Sciences of the United States of America 102, 14683-14688 (2005). Shows that ammonia-oxidzing archaea are ubiquitous in the oceans.

34. Leininger, S. et al. Archaea predominate among ammonia-oxidizing prokaryotes in soils. Nature 442, 806-809 (2006). Shows that archaea are major ammonia oxidizers in soils.

35. Lehtovirta-Morley, L.E., Stoecker, K., Vilcinskas, A., Prosser, J.I. \& Nicol, G.W. Cultivation of an obligate acidophilic ammonia oxidizer from a nitrifying acid soil. Proceedings of the National Academy of Sciences 108, 15892-15897 (2011). The discovery of an acidophilic ammonia oxidizer 
36. Tourna, M. et al. Nitrososphaera viennensis, an ammonia oxidizing archaeon from soil. Proceedings of the National Academy of Sciences 108, 8420-8425 (2011).

37. Burton, S.A. \& Prosser, J.I. Autotrophic ammonia oxidation at low pH through urea hydrolysis. Applied and Environmental Microbiology 67, 2952-2957 (2001).

38. Palatinszky, M. et al. Cyanate as an energy source for nitrifiers. Nature 524, 105-108 (2015).

39. Kits, K.D. et al. Kinetic analysis of a complete nitrifier reveals an oligotrophic lifestyle. Nature 549, 269-272 (2017).

40. Hakemian, A.S. \& Rosenzweig, A.C. The biochemistry of methane oxidation. Annu . Rev. Biochem. 76, 223-241 (2007).

41. Stein, L.Y.\& Klotz, M.G. Nitrifying and denitrifying pathways of methanotrophic bacteria. Biochemical Society Transactions 39, 1826-1831 (2011).

42. Stoecker, K. et al. Cohn's Crenothrix is a filamentous methane oxidizer with an unusual methane monooxygenase. Proceedings of the National Academy of Sciences of the United States of America 103, 2363-2367 (2006).

43. Oswald, K. et al. Crenothrix are major methane consumers in stratified lakes. ISME J (2017).

44. Simon, J. \& Klotz, M.G. Diversity and evolution of bioenergetic systems involved in microbial nitrogen compound transformations. Biochim Biophys Acta 1827, 114-35 (2013). An extensive overview of enzymes involved in microbial nitrogen transformations.

45. Kozlowski, J.A., Stieglmeier, M., Schleper, C., Klotz, M.G. \& Stein, L.Y. Pathways and key intermediates required for obligate aerobic ammonia-dependent chemolithotrophy in bacteria and Thaumarchaeota. The ISME Journal 10, 1836-45 (2016).

46. Kartal, B. et al. How to make a living from anaerobic ammonium oxidation. Fems Microbiology Reviews 37, 428-461 (2013).

47. Ren, T., Roy, R. \& Knowles, R. Production and Consumption of Nitric Oxide by Three Methanotrophic Bacteria. Applied and Environmental Microbiology 66, 38913897 (2000).

48. Nyerges, G. \& Stein, L.Y. Ammonia cometabolism and product inhibition vary considerably among species of methanotrophic bacteria. Fems Microbiology Letters 297, 131-136 (2009).

49. Schott, J., Griffin, B.M. \& Schink, B. Anaerobic phototrophic nitrite oxidation by Thiocapsa sp. strain KS1 and Rhodopseudomonas sp. strain LQ17. Microbiology 156, 2428-2437 (2010).

50. Strous, M. et al. Deciphering the evolution and metabolism of an anammox bacterium from a community genome. Nature 440, 790-794 (2006).

51. Strous, M. et al. Missing lithotroph identified as new planctomycete. Nature 400, 446-449 (1999). The discovery of anaerobic ammonium-oxidizing bacteria

52. Koch, H. et al. Growth of nitrite-oxidizing bacteria by aerobic hydrogen oxidation. Science 345, 1052-1054 (2014).

53. Koch, H. et al. Expanded metabolic versatility of ubiquitous nitrite-oxidizing bacteria from the genus Nitrospira. Proceedings of the National Academy of Sciences 112, 11371-11376 (2015).

54. Maia, L.B. \& Moura, J.J. How biology handles nitrite. Chem. Rev 114, 5273-5357 (2014).

55. Pachiadaki, M.G. et al. Major role of nitrite-oxidizing bacteria in dark ocean carbon fixation. Science 358, 1046-1051 (2017).

56. Philippot, L., Hallin, S. \& Schloter, M. Ecology of denitrifying prokaryotes in agricultural soil. Advances in Agronomy 96, 249-305 (2007). 
57. Lam, P. \& Kuypers, M.M.M. in Annual Review of Marine Science, Vol 3 317-345 (2011).

58. Kraft, B. et al. The environmental controls that govern the end product of bacterial nitrate respiration. Science 345, 676-679 (2014).

59. Lundberg, J.O., Weitzberg, E. \& Gladwin, M.T. The nitrate-nitrite-nitric oxide pathway in physiology and therapeutics. Nature reviews Drug discovery 7, 156-167 (2008).

60. Moreno-Vivian, C., Cabello, P., Martinez-Luque, M., Blasco, R. \& Castillo, F. Prokaryotic nitrate reduction: molecular properties and functional distinction among bacterial nitrate reductases. J Bacteriol 181, 6573-84 (1999).

61. Preisler, A. et al. Biological and chemical sulfide oxidation in a Beggiatoa inhabited marine sediment. The ISME Journal 1, 341-353 (2007).

62. Tsementzi, D. et al. SAR11 bacteria linked to ocean anoxia and nitrogen loss. Nature 536, 179-183 (2016).

63. Lam, P. et al. Revising the nitrogen cycle in the Peruvian oxygen minimum zone. Proceedings of the National Academy of Sciences 106, $4752-4757$ (2009).

64. Bristow, L.A. et al. N2 production rates limited by nitrite availability in the Bay of Bengal oxygen minimum zone. Nature Geoscience 10, 24-29 (2017).

65. Zumft, W.G. Cell biology and molecular basis of denitrification. Microbiology and Molecular Biology Reviews 61, 533-616 (1997).

66. Haroon, M.F. et al. Anaerobic oxidation of methane coupled to nitrate reduction in a novel archaeal lineage. Nature 500, 567-570 (2013). The discovery of nitratereducing methanotrophic archaea.

67. Ettwig, K.F. et al. Archaea catalyze iron-dependent anaerobic oxidation of methane. Proceedings of the National Academy of Sciences 113, 12792-12796 (2016).

68. Cardoso, R.B. et al. Sulfide oxidation under chemolithoautotrophic denitrifying conditions. Biotechnology and Bioengineering 95, 1148-1157 (2006).

69. Weber, K.A., Achenbach, L.A. \& Coates, J.D. Microorganisms pumping iron: anaerobic microbial iron oxidation and reduction. Nature Reviews Microbiology 4 , 752-764 (2006).

70. Gruber, N. The marine nitrogen cycle: overview and challenges. Nitrogen in the marine environment 2, 1-50 (2008).

71. Stolz, J.F. \& Basu, P. Evolution of nitrate reductase: molecular and structural variations on a common function. Chembiochem 3, 198-206 (2002).

72. Malm, S. et al. The roles of the nitrate reductase NarGHJI, the nitrite reductase NirBD and the response regulator GlnR in nitrate assimilation of Mycobacterium tuberculosis. Microbiology 155, 1332-1339 (2009).

73. Blöchl, E. et al. Pyrolobus fumarii, gen. and sp. nov., represents a novel group of archaea, extending the upper temperature limit for life to 113 C. Extremophiles 1, 1421 (1997).

74. Kamp, A., de Beer, D., Nitsch, J.L., Lavik, G. \& Stief, P. Diatoms respire nitrate to survive dark and anoxic conditions. Proceedings of the National Academy of Sciences 108, 5649-5654 (2011).

75. Zhou, Z. et al. Ammonia fermentation, a novel anoxic metabolism of nitrate by fungi. Journal of Biological Chemistry 277, 1892-1896 (2002).

76. Tikhonova, T.V. et al. Molecular and catalytic properties of a novel cytochrome c nitrite reductase from nitrate-reducing haloalkaliphilic sulfur-oxidizing bacterium Thioalkalivibrio nitratireducens. Biochimica et Biophysica Acta (BBA)-Proteins and Proteomics 1764, 715-723 (2006). 
77. Atkinson, S.J., Mowat, C.G., Reid, G.A. \& Chapman, S.K. An octaheme c-type cytochrome from Shewanella oneidensis can reduce nitrite and hydroxylamine. FEBS

78. Einsle, O. et al. Structure of cytochrome c nitrite reductase. Nature 400, 476-480 (1999).

79. Haase, D., Hermann, B., Einsle, O. \& Simon, J. Epsilonproteobacterial hydroxylamine oxidoreductase ( $\varepsilon \mathrm{Hao})$ : characterization of a 'missing link' in the multihaem cytochrome c family. Molecular Microbiology 105, 127-138 (2017).

80. Tiedje, J.M. in Biology of Anaerobic Microorganisms (ed. Zehnder, A.J.B.) 179-244 (Wiley, New York, NY, USA, 1988).

81. Brunet, R. \& Garcia-Gil, L. Sulfide-induced dissimilatory nitrate reduction to ammonia in anaerobic freshwater sediments. Fems Microbiology Ecology 21, 131-138 (1996).

82. Seitz, H.-J. \& Cypionka, H. Chemolithotrophic growth ofDesulfovibrio desulfuricans with hydrogen coupled to ammonification of nitrate or nitrite. Archives of Microbiology 146, 63-67 (1986).

83. Robertson, E.K., Roberts, K.L., Burdorf, L.D.W., Cook, P. \& Thamdrup, B. Dissimilatory nitrate reduction to ammonium coupled to $\mathrm{Fe}(\mathrm{II})$ oxidation in sediments of a periodically hypoxic estuary. Limnology and Oceanography 61, 365-381 (2016).

84. Rütting, T., Boeckx, P., Müller, C. \& Klemedtsson, L. Assessment of the importance of dissimilatory nitrate reduction to ammonium for the terrestrial nitrogen cycle.

Biogeosciences 8, 1779-1791 (2011).

85. Burgin, A.J. \& Hamilton, S.K. Have we overemphasized the role of denitrification in aquatic ecosystems? A review of nitrate removal pathways. Frontiers in Ecology and the Environment 5, 89-96 (2007).

86. Lomas, M.W. \& Lipschultz, F. Forming the primary nitrite maximum: Nitrifiers or phytoplankton? Limnology and Oceanography 51, 2453-2467 (2006).

87. Graf, D.R., Jones, C.M. \& Hallin, S. Intergenomic comparisons highlight modularity of the denitrification pathway and underpin the importance of community structure for $\mathrm{N}_{2} \mathrm{O}$ emissions. PloS one 9, e114118 (2014).

88. Bartossek, R., Nicol, G.W., Lanzen, A., Klenk, H.P. \& Schleper, C. Homologues of nitrite reductases in ammonia-oxidizing archaea: diversity and genomic context. Environmental Microbiology 12, 1075-1088 (2010).

89. Kartal, B. \& Keltjens, J.T. Anammox Biochemistry: a Tale of Heme c Proteins. Trends in Biochemical Sciences 41, 998-1011 (2016).

90. Fang, F.C. Antimicrobial reactive oxygen and nitrogen species: concepts and controversies. Nature Reviews Microbiology 2, 820-832 (2004).

91. Hallin, S., Philippot, L., Löffler, F.E., Sanford, R.A. \& Jones, C.M. Genomics and Ecology of Novel $\mathrm{N}_{2} \mathrm{O}$-Reducing Microorganisms. Trends in microbiology (2017).

92. Ravishankara, A.R., Daniel, J.S. \& Portmann, R.W. Nitrous Oxide $\left(\mathrm{N}_{2} \mathrm{O}\right)$ : The Dominant Ozone-Depleting Substance Emitted in the 21 st Century. Science 326, 123 125 (2009).

93. Saraiva, L.M., Vicente, J.B. \& Teixeira, M. The role of the flavodiiron proteins in microbial nitric oxide detoxification. Advances in microbial physiology 49, 77-129 (2004).

94. Rodrigues, R. et al. Desulfovibrio gigas flavodiiron protein affords protection against nitrosative stress in vivo. Journal of Bacteriology 188, 2745-2751 (2006).

95. Shoun, H., Fushinobu, S., Jiang, L., Kim, S.-W. \& Wakagi, T. Fungal denitrification and nitric oxide reductase cytochrome P450nor. Phil. Trans. R. Soc. B 367, 1186-1194 (2012). 
96. Wang, J. et al. The roles of the hybrid cluster protein, Hcp, and its reductase, Hcr, in against nitrosative stress. Molecular Microbiology (2016).

97. Hino, T. et al. Structural basis of biological $\mathrm{N} 2 \mathrm{O}$ generation by bacterial nitric oxide reductase. Science 330, 1666-1670 (2010).

98. Matsumoto, Y. et al. Crystal structure of quinol-dependent nitric oxide reductase from Geobacillus stearothermophilus. Nature Structural \& Molecular Biology 19, 238-245 (2012).

99. Al-Attar, S. \& de Vries, S. An electrogenic nitric oxide reductase. FEBS Letters 589, 2050-2057 (2015).

100. Liu, S. et al. Abiotic Conversion of Extracellular NH2OH Contributes to N2O Emission during Ammonia Oxidation. Environmental Science \& Technology (2017).

101. Stocker, T.F. et al. IPCC, 2013: Climate Change 2013: The Physical Science Basis. Contribution of Working Group I to the Fifth Assessment Report of the Intergovernmental Panel on Climate Change Cambridge University Press, Cambridge, United Kingdom and New York, NY, USA, 1535 pp (2013).

102. Davidson, E.A. The contribution of manure and fertilizer nitrogen to atmospheric nitrous oxide since 1860. Nature Geoscience 2, 659-662 (2009).

103. Crutzen, P., Mosier, A., Smith, K. \& Winiwarter, W. $\mathrm{N}_{2} \mathrm{O}$ release from agro-biofuel production negates global warming reduction by replacing fossil fuels. Atmos. Chem. Phys 8, 389-395 (2008).

104. Ettwig, K.F. et al. Bacterial oxygen production in the dark. Frontiers in microbiology 3, 273 (2012).

105. Zumft, W.G. \& Kroneck, P.M. Respiratory transformation of nitrous oxide (N 2 O) to dinitrogen by Bacteria and Archaea. Advances in microbial physiology 52, 107-227 (2006).

106. Cabello, P., Roldan, M.D. \& Moreno-Vivian, C. Nitrate reduction and the nitrogen cycle in archaea. Microbiology-Sgm 150, 3527-3546 (2004).

107. Simon, J., Einsle, O., Kroneck, P.M. \& Zumft, W.G. The unprecedented nos gene cluster of Wolinella succinogenes encodes a novel respiratory electron transfer pathway to cytochrome c nitrous oxide reductase. FEBS Letters 569, 7-12 (2004).

108. Sanford, R.A. et al. Unexpected nondenitrifier nitrous oxide reductase gene diversity and abundance in soils. Proceedings of the National Academy of Sciences of the United States of America 109 (2012).

109. Jones, C.M. et al. Recently identified microbial guild mediates soil N2O sink capacity. Nature Climate Change 4 (2014).

110. Piña-Ochoa, E. et al. Widespread occurrence of nitrate storage and denitrification among Foraminifera and Gromiida. Proceedings of the National Academy of Sciences 107, 1148-1153 (2010).

111. Philippot, L., Andert, J., Jones, C.M., Bru, D. \& Hallin, S. Importance of denitrifiers lacking the genes encoding the nitrous oxide reductase for $\mathrm{N} 2 \mathrm{O}$ emissions from soil. Global Change Biology 17, 1497-1504 (2011).

112. Codispoti, L. \& Christensen, J. Nitrification, denitrification and nitrous oxide cycling in the eastern tropical South Pacific Ocean. Marine Chemistry 16, 277-300 (1985).

113. Van de Graaf, A.A., de Bruijn, P., Robertson, L.A., Jetten, M.S. \& Kuenen, J.G. Autotrophic growth of anaerobic ammonium-oxidizing micro-organisms in a fluidized bed reactor. Microbiology 142, 2187-2196 (1996).

114. Mulder, A., Vandegraaf, A.A., Robertson, L.A. \& Kuenen, J.G. Anaerobic ammonium oxidation discovered in a denitrifying fluidized bed reactor. Fems Microbiology Ecology 16, 177-183 (1995). The discovery of anaerobic ammonium oxidation. 
115. Dietl, A. et al. The inner workings of the hydrazine synthase multiprotein complex. Nature 527, 394-397 (2015).

116. Jetten, M.S.M., den Camp, H.J.M.O., Gijs Kuenen, J. \& Strous, M. in Bergey's Manual of Systematics of Archaea and Bacteria (John Wiley \& Sons, Ltd, 2015).

117. Harhangi, H.R. et al. Hydrazine synthase, a unique phylomarker with which to study the presence and biodiversity of anammox bacteria. Applied and Environmental Microbiology 78, 752-758 (2012).

118. Wang, Y. et al. Co-occurrence and distribution of nitrite-dependent anaerobic ammonium and methane-oxidizing bacteria in a paddy soil. Fems Microbiology Letters 336, 79-88 (2012).

119. Maalcke, W.J. et al. Characterization of anammox hydrazine dehydrogenase, a key N2-producing enzyme in the global nitrogen cycle. Journal of Biological Chemistry 291, 17077-17092 (2016).

120. Neumann, $\mathrm{S}$. et al. Isolation and characterization of a prokaryotic cell organelle from the anammox bacterium Kuenenia stuttgartiensis. Molecular Microbiology 94, 794802 (2014).

121. de Almeida, N.M. et al. Membrane-bound electron transport systems of an anammox bacterium: A complexome analysis. Biochimica et Biophysica Acta (BBA)Bioenergetics 1857, 1694-1704 (2016).

122. de Almeida, N.M. et al. Immunogold localization of key metabolic enzymes in the anammoxosome and on the tubule-like structures of Kuenenia stuttgartiensis. Journal of Bacteriology 197, 2432-2441 (2015).

123. Kuypers, M.M. et al. Anaerobic ammonium oxidation by anammox bacteria in the Black Sea. Nature 422, 608-611 (2003). The first detection of anaerobic ammonium-oxidizing bacteria in the environment.

124. Kuypers, M.M.M. et al. Massive nitrogen loss from the Benguela upwelling system through anaerobic ammonium oxidation. Proceedings of the National Academy of Sciences of the United States of America 102, 6478-6483 (2005).

125. Devol, A.H. Nitrogen cycle: Solution to a marine mystery. Nature 422, 575-576 (2003).

126. Zhu, G. et al. Anaerobic ammonia oxidation in a fertilized paddy soil. The ISME Journal 5, 1905-1912 (2011).

127. Bronk, D.A. \& Steinberg, D.K. in Nitrogen in the Marine Environment (2nd Edition) 385-467 (Academic Press, San Diego, 2008).

128. Sunagawa, S. et al. Structure and function of the global ocean microbiome. Science 348, 1261359 (2015).

129. Gruber, N. \& Galloway, J.N. An Earth-system perspective of the global nitrogen cycle. Nature 451, 293-296 (2008).

130. Vaksmaa, A. et al. Enrichment of anaerobic nitrate-dependent methanotrophic 'Candidatus Methanoperedens nitroreducens' archaea from an Italian paddy field soil. Applied Microbiology and Biotechnology 101, 7075-7084 (2017).

131. Martens-Habbena, W., Berube, P.M., Urakawa, H., de la Torre, J.R. \& Stahl, D.A. Ammonia oxidation kinetics determine niche separation of nitrifying Archaea and Bacteria. Nature 461, 976-979 (2009).

132. Schleper, C. \& Nicol, G.W. Ammonia-oxidising archaea-physiology, ecology and evolution. Advances in microbial physiology 57, 41 (2010).

133. Pjevac, P. et al. AmoA-targeted polymerase chain reaction primers for the specific detection and quantification of comammox Nitrospira in the environment. Frontiers in microbiology 8, 1508 (2017). 
134. Oshiki, M. et al. Nitrate-dependent ferrous iron oxidation by anaerobic ammonium oxidation (anammox) bacteria. Applied and Environmental Microbiology 79, 40874093 (2013).

135. Ferousi, C. et al. Iron assimilation and utilization in anaerobic ammonium oxidizing bacteria. Current opinion in chemical biology 37, 129-136 (2017).

136. Jensen, M.M. et al. Intensive nitrogen loss over the Omani Shelf due to anammox coupled with dissimilatory nitrite reduction to ammonium. The ISME Journal 5, 16601670 (2011).

137. Jones, C.M., Graf, D.R.H., Bru, D., Philippot, L. \& Hallin, S. The unaccounted yet abundant nitrous oxide-reducing microbial community: a potential nitrous oxide sink. Isme Journal 7 (2013).

138. Heylen, K. \& Keltjens, J. Redundancy and modularity in membrane-associated dissimilatory nitrate reduction in Bacillus. Frontiers in Microbiology. 3 (2012).

139. Canfield, D.E., Thamdrup, B. \& Kristensen, E. Aquatic Geomicrobiology (Elsevier Academic Press, 2005).

140. Sutton, M.A. et al. The European nitrogen assessment: sources, effects and policy perspectives (Cambridge University Press, 2011).

141. Canfield, D.E., Glazer, A.N. \& Falkowski, P.G. The evolution and future of Earth's nitrogen cycle. Science 330, 192-196 (2010).

142. Duce, R.A. et al. Impacts of Atmospheric Anthropogenic Nitrogen on the Open Ocean. Science 320, 893-897 (2008).

143. Grosskopf, T. et al. Doubling of marine dinitrogen-fixation rates based on direct measurements. Nature 488, 361-364 (2012).

144. McGroddy, M.E., Daufresne, T.\& Hedin, L.O. Scaling of C:N:P stoichiometry in forests worldwide: implications of terrestrial redfield-type ratios. Ecology 85, 23902401 (2004).

145. Rittmann, B.E. \& McCarty, P.L. Environmental biotechnology: principles and applications (Tata McGraw-Hill Education, 2012).

146. Kartal, B., Kuenen, J.v. \& Van Loosdrecht, M. Sewage treatment with anammox. Science 328, 702-703 (2010).

147. Lackner, S. et al. Full-scale partial nitritation/anammox experiences-an application survey. Water Research 55, 292-303 (2014).

148. Park, H.-D., Wells, G.F., Bae, H., Criddle, C.S. \& Francis, C.A. Occurrence of Ammonia-Oxidizing Archaea in Wastewater Treatment Plant Bioreactors. Applied and Environmental Microbiology 72, 5643-5647 (2006).

149. Luesken, F.A. et al. Simultaneous nitrite-dependent anaerobic methane and ammonium oxidation processes. Applied and Environmental Microbiology 77, 68026807 (2011).

150. Starkenburg, S.R., Arp, D.J. \& Bottomley, P.J. Expression of a putative nitrite reductase and the reversible inhibition of nitrite-dependent respiration by nitric oxide in Nitrobacter winogradskyi Nb-255. Environmental Microbiology 10, 3036-3042 (2008).

151. Freitag, A. \& Bock, E. Energy conservation in Nitrobacter. Fems Microbiology Letters 66, 157-162 (1990).

152. Wijma, H.J., Canters, G.W., de Vries, S. \& Verbeet, M.P. Bidirectional catalysis by copper-containing nitrite reductase. Biochemistry 43, 10467-10474 (2004).

153. Sousa, F.L. et al. The superfamily of heme-copper oxygen reductases: types and evolutionary considerations. Biochimica et Biophysica Acta (BBA)-Bioenergetics 1817, 629-637 (2012). 
154. Rothery, R.A., Workun, G.J. \& Weiner, J.H. The prokaryotic complex iron-sulfur molybdoenzyme family. Biochimica et Biophysica Acta (BBA) - Biomembranes 1778, 1897-1929 (2008).

155. Ishii, S., Ikeda, S., Minamisawa, K. \& Senoo, K. Nitrogen cycling in rice paddy environments: past achievements and future challenges. Microbes and environments 26, 282-292 (2011).

\section{Acknowledgement}

We thank Wiebke Mohr and Jana Milucka (Max Planck Institute for Marine Microbiology, Bremen, Germany) for discussions. This work was supported by the Max Planck Society (MPG) and the European Research Council Grant 640422 to B.K.

\section{Competing financial interest statement}

The authors declare no competing financial interest.

\section{Author contributions}

M.M.M.K., H.K.M. and B.K. researched data for the article, made substantial contributions to discussions of the content, wrote the article and reviewed and edited the manuscript before submission.

\section{Publisher's note}

Springer Nature remains neutral with regard to jurisdictional claims in published maps and institutional affiliations.

Nature Reviews Microbiology thanks Holger Daims, Sarah Hallin and the other anonymous reviewer(s) for their contribution to the peer review of this work.

\section{Box 1. Biogeochemical nitrogen cycling: global inventories, processes and fluxes.}

The largest global nitrogen inventory, with $1.8 \times 10^{10} \mathrm{Tg}$ nitrogen, is ammonia bound in rocks and sediments ${ }^{139}$. Although this bound ammonia becomes available upon erosion, it has a minor role in annual biogeochemical nitrogen cycling. Whereas the terrestrial inventory of freely accessible ammonia is unknown ${ }^{140}$, the marine inventory ${ }^{70,139}$ is estimated to be between 340 
and $3600 \mathrm{Tg}$ nitrogen (see grey numbers in the figure). The largest freely accessible global

909 nitrogen inventory is dinitrogen gas with $3.9 \times 10^{9} \mathrm{Tg}$ nitrogen followed by organic nitrogen,

910 nitrate, and nitrous oxide inventories ${ }^{70,139}$. Global nitrite and nitric oxide inventories are 911 negligible.

912 Biogeochemical nitrogen cycling between these inventories is often attributed to the following

913 six distinct nitrogen-transforming processes: assimilation, ammonification, nitrification,

914 denitrification, anaerobic ammonium oxidation (anammox) and nitrogen-fixation (see the

915 figure). We estimated the annual nitrogen fluxes for a number of these processes from the 916 available literature ${ }^{129,141-143}$ and based on simple assumptions (see below). In the figure, the 917 fluxes between major nitrogen species are shown in Tg nitrogen per year, with green, blue and 918 red numbers referring to terrestrial, marine and anthropogenic nitrogen fluxes, respectively. The 919 best-defined fluxes involve nitrogen loss and fixation, because they have been the focus of 920 many studies ${ }^{129,141,143}$. These fluxes are comparatively small (see the figure) but regulate the 921 availability of bioavailable nitrogen, which largely controls the removal of atmospheric $\mathrm{CO}_{2}$ 922 through the biological carbon pump ${ }^{129}$. Current estimates suggest that biological $\mathrm{N}_{2}$-fixation 923 ( 300Tg nitrogen $\left.\mathrm{y}^{-1}\right)$ combined with industrial nitrogen-fixation and fossil fuel burning $(\sim 125$ 924 Tg nitrogen $\left.\mathrm{y}^{-1}\right)^{129,143}$ exceeds the production of dinitrogen gas by anammox and denitrification $925\left(\sim 350 \mathrm{Tg} \text { nitrogen } \mathrm{y}^{-1}\right)^{129,141}$. Not all nitrous oxide produced from nitric oxide reduction is 926 further reduced to dinitrogen gas. The resulting nitrous oxide release from the marine and

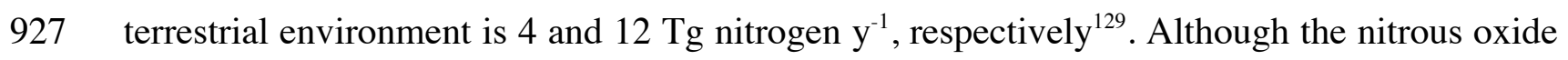
928 flux is small compared to the other nitrogen fluxes, it has a profound effect on the environment because nitrous oxide is the main ozone depleting agent and a powerful greenhouse gas ${ }^{92}$.

930 As shown in the figure, the nitrogen-transforming processes have vastly different fluxes and do 931 not form one balanced nitrogen cycle as often depicted in papers and textbooks. The largest 932 nitrogen fluxes are associated with the interconversion of ammonia and organic nitrogen. In the 933 marine environment alone, the fluxes associated with ammonification and ammonium 934 assimilation are an order of magnitude larger $\left(\sim 8800 \mathrm{Tg} \text { nitrogen } \mathrm{y}^{-1}\right)^{142}$ than marine nitrogen 935 loss and gain combined $\left(\sim 300 \mathrm{Tg} \text { nitrogen } \mathrm{y}^{-1}\right)^{141}$. Another substantial nitrogen flux is associated 936 with the oxidation of ammonia to nitrate via nitric oxide and nitrite (that is, nitrification). 937 Marine nitrification is associated with a flux of $\sim 2000 \mathrm{Tg}$ nitrogen per year, which explains 938 why marine ammonia-oxidizing archaea are among the most abundant microorganisms even 939 though ammonia concentrations are low in the ocean. Nitrate-assimilation related fluxes are in 940 the same order of magnitude. Marine phytoplankton accounts for $2000 \mathrm{Tg}$ nitrate reduced per 941 year ${ }^{142}$. Compared to this, the fluxes associated with dissimilatory nitrate reduction to 
942 ammonium are most likely smaller. Although there are no available estimates for the terrestrial 943 environment, assimilation related fluxes are likely six times smaller due to the lower nitrogen 944 requirement of land plants, which require about 1 molecule of nitrogen for every 40 carbon 945 molecules fixed ${ }^{144}$, compared to 1 molecule nitrogen per 6.6 molecules of carbon fixed by 946 marine algae. Assuming steady state conditions (when gain of a nitrogen compound equals its 947 loss), we estimated the terrestrial nitrification and ammonification fluxes by dividing the marine 948 fluxes by six.

\section{Box 2. Nitrogen removal by microorganisms in wastewater treatment}

951 Since the industrial revolution, agriculture, burning of fossil fuel and domestic and industrial 952 wastewater production have been the major drivers of nitrogen pollution, which severely affects 953 life on earth ${ }^{141,142}$. Nitrogen has been recognized as an important pollutant in wastewater only 954 in the last 40 years, when it became clear that excess nitrogen leads to eutrophication and fish 955 mortality due to ammonia toxicity. Consequently, nitrogen-removing systems were added to 956 many wastewater treatment plants, which were originally used to remove organic carbon.

957 Nevertheless, most conventional wastewater treatment plants do not remove nitrogen.

958 In contrast to most natural ecosystems, in which precious nitrogen is recycled and retained, 959 nitrogen-removing treatment plants are designed to convert ammonium to dinitrogen gas, which 960 is lost to the atmosphere. In these treatment plants, organic carbon is removed first. This results 961 in organic carbon-poor and ammonium-rich wastewater, which is fed into a nitrogen-removal 962 system. Conventional systems rely on nitrification $\left(\mathrm{NH}_{4}{ }^{+} \rightarrow \mathrm{NO}_{2}{ }^{-} \rightarrow \mathrm{NO}_{3}{ }^{-}\right)$to oxidize ammonium 963 to nitrate, which is subsequently reduced to dinitrogen gas by denitrification $\left(\mathrm{NO}_{3}{ }^{-} \rightarrow \mathrm{NO}_{2}{ }^{-}\right.$ $964 \rightarrow \mathrm{NO} \rightarrow \mathrm{N}_{2} \mathrm{O} \rightarrow \mathrm{N}_{2}$ ). Nitrification requires extensive aeration to create conditions that are 965 suitable for ammonium oxidation to nitrate (2 molecules of $\mathrm{O}_{2}$ is needed per molecule of 966 ammonium). Subsequently, external organic carbon (often methanol) is added to induce 967 heterotrophic denitrification, which reduces nitrate to $\mathrm{N}_{2}$. Hence, conventional nitrogen removal 968 is costly, energy- and resource-intensive, and also produces nitrous oxide, which contributes to 969 global warming. To alleviate these problems, different reactor configurations have been 970 implemented to minimize external carbon addition and aeration. For example, in some systems, 971 part of the raw wastewater, which is rich in organic carbon, is fed directly to the denitrification

972 step or in others, intermittent aeration is used to promote nitrification and denitrification in a 973 single tank $\mathrm{k}^{145}$.

974 In the last decade, anaerobic ammonium oxidation (anammox) emerged as an alternative 975 process for nitrogen removal. In compact bioreactors, aerobic ammonia-oxidizing bacteria, 
such as Nitrosomonas europea, convert half of the available ammonia to nitrite under oxygen

977 limitation, which is termed 'partial-nitritation'. This is followed by the conversion of nitrite 978 with the remaining ammonium to dinitrogen gas by bacteria performing the anammox process, 979 such as Kuenenia stuttgartiensis (solid arrows, see the figure) ${ }^{146}$. In these partial nitritation980 anammox systems, nitrate production by aerobic nitrite oxidizers such as Nitrospira spp. or 981 Nitrobacter spp. is undesired as it decreases the efficiency of nitrogen removal. Oxygen-limited 982 partial-nitritation-anammox reactors have lower aeration requirements than conventional 983 nitrogen-removal systems, do not require organic carbon addition, and produce less nitrous 984 oxide. Currently, partial-nitritation-anammox systems are increasingly applied to ammonium985 rich wastewaters ${ }^{146,147}$, such as effluents from anaerobic sludge digesters [G]. Implementation 986 of these systems in full-scale municipal wastewater treatment, which have much lower 987 ammonium concentrations, could pave the way to more sustainable sewage treatment ${ }^{146}$.

988 Some of the recently discovered nitrogen-cycling microorganisms could also be applied in 989 wastewater treatment. Archaea that oxidize ammonia to nitrite and bacteria that oxidize 990 ammonia to nitrate (in the comammox process) have been detected in nitrogen-removing 991 wastewater treatment plants ${ }^{133,148}$ but their role in these systems is unclear. In oxygen-limited 992 nitrogen-removal systems, such as partial-nitritation-anammox bioreactors, bacteria preforming 993 comammox ${ }^{12,13,39}$ will most likely act as conventional ammonia oxidizers that produce nitrite. 994 Exciting new possibilities for wastewater treatment are offered by the newly discovered nitrite995 and nitrate-dependent anaerobic methane-oxidizing microorganisms ${ }^{66,149}$. A bioreactor that 996 combines anaerobic methanotrophs, such as Candidatus Methylomirabilis spp. and Candidatus 997 Methanoperedens spp. with microorganisms that perform the anammox process could 998 simultaneously remove ammonium, nitrate and methane (dashed arrows; see the figure). Such 999 co-cultures have already been established under laboratory conditions; however, a full-scale 1000 wastewater treatment system has not been implemented ${ }^{66,149}$. In these systems, aerobic methane 1001 oxidizers such as Methylomonas spp. would also contribute to methane removal.

1002 Fundamental physiological and biochemical research into nitrogen-cycling microorganisms 1003 and their application have always progressed hand in hand - newly discovered 1004 microorganisms led to more efficient and sustainable treatment systems, and vice versa. It is 1005 apparent that this trend will continue to help safeguard the environment for future generations.

\section{Box 3: Undiscovered biochemical reactions}

1007 Numerous new microbial nitrogen-transforming reactions and pathways have been discovered 1008 in the last decade. Based on thermodynamic considerations further exergonic [G] reactions exist 1009 that could be exploited by microorganisms (Equations 15-26). Whereas some reactions could 
1010 be catalyzed by known enzymes, others would require hitherto unknown biochemistry (Eq. 15-

1011 19, 25 and 26). For example, nitrate-dependent ammonium oxidation (Eq. 15) cannot proceed

1012 through the known anaerobic ammonium oxidation pathway because ammonia first needs to be

1013 oxidized to the intermediate hydroxylamine or a similar oxygen containing species ${ }^{46}$.

1014 Eq $155 \mathrm{NH}_{4}^{+}+3 \mathrm{NO}_{3}^{-} \rightarrow 4 \mathrm{~N}_{2}+9 \mathrm{H}_{2} \mathrm{O}+2 \mathrm{H}^{+} \quad\left(\Delta \mathrm{G}^{0^{\prime}}=-297 \mathrm{~kJ} / \mathrm{mol} \mathrm{NH}_{4}{ }^{+}\right)$

1015 Similarly, novel biochemical pathways for ammonia activation would be necessary for iron-

1016 and manganese-dependent ammonium oxidation (Eq. 16-19).

1017

1018

1019

1020

1021

1022

1023

1024

1025

1026

1027

1028

1029

1030

1031

1032

1033

1034

1035

1036

1037

1038

1039

1040

1041

1042

1043

1044

1045

1046

1047

1048

1049
$\mathrm{Eq} 16 \mathrm{NH}_{4}^{+}+6 \mathrm{Fe}^{3+}+2 \mathrm{H}_{2} \mathrm{O} \rightarrow \mathrm{NO}_{2}^{-}+6 \mathrm{Fe}^{2+}+8 \mathrm{H}^{+}$
$\left(\Delta \mathrm{G}^{0^{\prime}}=-247 \mathrm{~kJ} / \mathrm{mol} \mathrm{NH}_{4}^{+}\right)$
Eq $172 \mathrm{NH}_{4}^{+}+6 \mathrm{Fe}^{3+} \rightarrow \mathrm{N}_{2}+6 \mathrm{Fe}^{2+}+8 \mathrm{H}^{+}$
$\left(\Delta \mathrm{G}^{0^{\prime}}=-303 \mathrm{~kJ} / \mathrm{mol} \mathrm{NH}_{4}^{+}\right)$
$\mathrm{Eq} 18 \mathrm{NH}_{4}^{+}+3 \mathrm{MnO}_{2}+4 \mathrm{H}^{+} \rightarrow \mathrm{NO}_{2}^{-}+3 \mathrm{Mn}^{2+}+4 \mathrm{H}_{2} \mathrm{O}$
$\left(\Delta \mathrm{G}^{0^{\prime}}=-60 \mathrm{~kJ} / \mathrm{mol} \mathrm{NH}_{4}^{+}\right)$
Eq $192 \mathrm{NH}_{4}^{+}+3 \mathrm{MnO}_{2}+4 \mathrm{H}^{+} \rightarrow \mathrm{N}_{2}+3 \mathrm{Mn}^{2+}+6 \mathrm{H}_{2} \mathrm{O}$
$\left(\Delta \mathrm{G}^{0^{\prime}}=-249 \mathrm{~kJ} / \mathrm{mol} \mathrm{NH}_{4}{ }^{+}\right)$

On the other hand, several disproportionation [G] reactions (Eq. 20-24) could be carried out by known microorganisms using the existing biochemical machinery. Anaerobic ammoniumoxidizing bacteria could perform nitrite (Eq. 20) and nitric oxide (Eq. 21) disproportionation ${ }^{46}$.
$\mathrm{Eq} 20 \quad 5 \mathrm{NO}_{2}^{-}+2 \mathrm{H}^{+} \rightarrow \mathrm{N}_{2}+3 \mathrm{NO}_{3}^{-}+2 \mathrm{H}_{2} \mathrm{O}$
$\left(\Delta \mathrm{G}^{0^{\prime}}=-60 \mathrm{~kJ} / \mathrm{mol} \mathrm{NO}_{2}^{-}\right)$
Eq $2110 \mathrm{NO}+2 \mathrm{H}_{2} \mathrm{O} \rightarrow 3 \mathrm{~N}_{2}+4 \mathrm{NO}_{3}^{-}+4 \mathrm{H}^{+}$
$\left(\Delta \mathrm{G}^{0^{\prime}}=-100 \mathrm{~kJ} / \mathrm{mol} \mathrm{NO}\right)$

Similarly, disproportionation of nitrite into nitrous oxide and nitrate (Eq. 22), nitric oxide into nitrite and nitrous oxide (Eq. 23) or nitrate and nitrous oxide (Eq. 24) could theoretically be carried out by aerobic nitrite-oxidizing bacteria.
$\mathrm{Eq} 224 \mathrm{NO}_{2}^{-}+2 \mathrm{H}^{+} \rightarrow \mathrm{N}_{2} \mathrm{O}+2 \mathrm{NO}_{3}{ }^{-}+\mathrm{H}_{2} \mathrm{O}$
$\left(\Delta \mathrm{G}^{0^{\prime}}=-32 \mathrm{~kJ} / \mathrm{mol} \mathrm{NO}_{2}{ }^{-}\right)$
Eq $234 \mathrm{NO}+\mathrm{H}_{2} \mathrm{O} \rightarrow 2 \mathrm{NO}_{2}{ }^{-}+\mathrm{N}_{2} \mathrm{O}+2 \mathrm{H}^{+}$
$\left(\Delta \mathrm{G}^{0^{\prime}}=-40 \mathrm{~kJ} / \mathrm{mol} \mathrm{NO}\right)$
$\mathrm{Eq} 248 \mathrm{NO}+\mathrm{H}_{2} \mathrm{O} \rightarrow 2 \mathrm{NO}_{3}{ }^{-}+3 \mathrm{~N}_{2} \mathrm{O}+2 \mathrm{H}^{+}$
$\left(\Delta \mathrm{G}^{0^{\prime}}=-56 \mathrm{~kJ} / \mathrm{mol} \mathrm{NO}\right)$

These microorganisms could use nitrite oxidoreductase to oxidize nitrite to nitrate and nitrite reductases present in Nitrobacter spp., Nitrococcus marinus, Nitrospira spp. and Nitrospina spp. could reduce nitrite to nitric oxide ${ }^{6}$. Nitric oxide oxidation has been observed in Nitrobacter spp. ${ }^{150,151}$ but it is unclear whether this reaction is biotic or abiotic and the responsible enzyme remains unknown. Nitric oxide oxidation to nitrite could also be catalyzed by $\mathrm{Cu}$-containing nitrite reductases (nirK), which are known to be bidirectional ${ }^{152}$. The remaining reaction, reduction of nitric oxide to nitrous oxide, can be carried out by terminal oxidases, which are evolutionarily related to nitric oxide reductases ${ }^{153}$.

Nitrous oxide, a potent greenhouse gas, is reduced to dinitrogen gas in the absence of oxygen, whereas it is assumed to be biologically stable under oxic conditions. Intriguingly, aerobic 
nitrous oxide oxidation to either nitrite or nitrate is thermodynamically feasible (Eq. 25, 26), but this reaction would also require a new biochemical pathway.
Eq $25 \mathrm{~N}_{2} \mathrm{O}+\mathrm{O}_{2}+\mathrm{H}_{2} \mathrm{O} \rightarrow 2 \mathrm{NO}_{2}^{-}+2 \mathrm{H}^{+}$
$\left(\Delta \mathrm{G}^{0^{\prime}}=-21 \mathrm{~kJ} / \mathrm{mol} \mathrm{N} \mathrm{N}_{2} \mathrm{O}\right)$
Eq $26 \mathrm{~N}_{2} \mathrm{O}+2 \mathrm{O}_{2}+\mathrm{H}_{2} \mathrm{O} \rightarrow 2 \mathrm{NO}_{3}{ }^{-}+2 \mathrm{H}^{+}$
$\left(\Delta \mathrm{G}^{0^{\prime}}=-89 \mathrm{~kJ} / \mathrm{mol} \mathrm{N} \mathrm{N}_{2} \mathrm{O}\right)$

The only way to identify microorganisms that catalyze these undiscovered reactions is to grow them under controlled laboratory conditions. It is clear that the physiology and biochemistry of nitrogen-transforming microorganisms will remain fertile fields of research for years to come.

Figure 1. Microbial transformations of nitrogen compounds. Microorganisms carry enzymes that perform fourteen redox reactions involving eight key inorganic nitrogen species of different oxidation states (enzyme-bound intermediates and their redox-states are not shown). The interconversion of ammonia and organic nitrogen does not involve a change in the redox state of the nitrogen atom. The reactions involve reduction (red), oxidation (blue) and disproportionation and comproportionation (green). The following enzymes perform the nitrogen transformations: assimilatory nitrate reductase (NAS, nas A and nirA); membranebound (NAR, narGH) and periplasmic (NAP, napA) dissimilatory nitrate reductases; nitrite oxidoreductase (NXR, $n x r A B$ ); nitric oxide oxidase (NOD, hmp); heme-containing (cd1-NIR, nirS) and copper-containing (Cu-NIR, nirK) nitrite reductases; cytochrome c-dependent (cNOR, cnorB), quinol-dependent (qNOR, norZ) and copper-containing quinol-dependent nitric oxide reductases $\left(\mathrm{Cu}_{\mathrm{A}} \mathrm{NOR}\right)$; $\mathrm{NADH}$-dependent cytochrome $\mathrm{P}_{450}$ nitric oxide reductase $\left(\mathrm{P}_{450} \mathrm{NOR}\right.$, p450nor); flavodiiron nitric oxide reductase $\left(\mathrm{NOR}_{\mathrm{VW}}\right.$, nor $\left.V W\right)$; hybrid cluster protein (HCP, hcp); hydroxylamine oxidoreductase (HAO, hao); hydroxylamine oxidase (HOX , hox); nitrous oxide reductase (NOS, nosZ); nitric oxide dismutase (NO-D, norZ); assimilatory nitrite reductase (cNIR); nas $B$ and $n i r B$ ); dissimilatory periplasmic cytochrome c nitrite reductase (ccNIR, nrfH); epsilon hydroxylamine oxidoreductase ( $\mathrm{HAO}$, haoA); octaheme nitrite reductase (ONR); octaheme tetrathionate reductase (OTR); molybdenum-iron (MoFe, nifHDK), iron-iron (FeFe, anfHGDK) and vanadium-iron (VFe, vnfHGDK) nitrogenases; hydrazine hydrolase $(\mathrm{HDH}, h d h)$; hydrazine synthase (HZS, hzsCBA); ammonia monooxygenase (AMO, amoCAB); particulate methane monooxyg2enase (pMMO, pmoBAC); cyanase (CYN, cynS); urease (URE, ureABC). 
1087 Figure 2. Enzymes catalyzing four key nitrogen cycling reactions. a. The molybdenum-iron

1088 (MoFe) nitrogenase enzyme contains the electron transfer protein (green; encoded by nifH) and 1089 the alpha- (magenta; encoded by nifD) and beta-subunits (purple; encoded by the nifK) of the 1090 catalytic enzyme. nifH is used to detect nitrogen fixing-microorganisms in the environment. 1091 The iron sulfur clusters mediate electron transfer to the catalytic center. The association and 1092 dissociation of the electron transfer and catalytic proteins requires the input of ATP. b. In the 1093 anaerobic ammonium-oxidizing bacterium Kuenenia stuttgartienis, electrons flow through the 1094 hemes of the octaheme hydroxylamine oxidase (HOX) (red arrows). Hemes belonging to 1095 different monomers are depicted in green, blue and gray. Heme 4 is the catalytic center. c. In 1096 the membrane-bound bacterial nitrate reductase (NAR), the catalytic dimer is encoded by narG 1097 and $n a r H$, whereas the membrane anchor is encoded by narI. narG is used to detect denitrifying 1098 microorganisms in the environment. Nitrate reduction to nitrite occurs in the cytoplasm and 1099 protons are translocated into the periplasm. Thereby, NAR contributes to the proton motive 1100 force. d. In Kuenenia stuttgartienis, $h z s A, h z s B$ and $h z s C$ encode a hydrazine synthase. The 1101 former two genes are used to detect anaerobic ammonium-oxidizing bacteria in the 1102 environment. This enzyme is proposed to perform a two-step reaction. It starts in the gamma 1103 subunit (gray) with the reduction of nitric oxide to hydroxylamine, which is transported through 1104 the substrate channel (brown) to the alpha subunit (green). The alpha subunit comproportionates 1105 hydroylamine with ammonia into hydrazine. Both reactions are catalyzed by cytochrome $c$-type 1106 heme proteins. Figure 2a was adapted from http://pdb101.rcsb.org/motm/26, 2b from Ref. 8, 2c adapted from Ref. 154, and 2d was adapted from Ref. 115.

Figure 3. Potential nitrogen-transforming microbial networks in different ecosystems. a)

1110 The open ocean gyres are vast nutrient-limited regions, in which nitrogen is extensively 1111 recycled. In the sunlit surface waters, cyanobacteria mainly assimilate ammonium and/or 1112 organic nitrogen compounds for growth. Viral lysis and grazing by mesozooplankton releases 1113 organic nitrogen (for example, urea), which is subsequently mineralized back to ammonium by 1114 heterotrophic bacteria. Nitrogen-fixing bacteria provide additional ammonium. In deeper 1115 waters, ammonium is oxidized to nitrate. Some of this nitrate diffuses up into the surface waters 1116 and is assimilated by phytoplankton. b) Marine oxygen minimum zones (OMZs) are found on 1117 the eastern boundaries of oceans, where wind-driven upwelling of nutrient rich waters 1118 stimulates primary productivity in the surface waters. The subsequent aerobic mineralization of 1119 sinking organic matters depletes oxygen in the underlying waters. Aerobic nitrifying 
communities that are well adapted to low oxygen-conditions perform ammonia oxidation to nitrite and nitrate. The OMZs are major regions of nitrogen loss due to the activity of anaerobic ammonium-oxidizing bacteria and to a lesser extent denitrification. Complex communities of microorganisms are involved in the denitrification process. c) Amongst the largest man-made ecosystems are agricultural fields that are used for crop production. Legumes are common crops and an important source of protein. They influence the microbial community in the surrounding soil by releasing organic carbon and live in symbiosis with $\mathrm{N}_{2}$-fixing microorganisms, such as Bradyrhizobium spp.. Ammonium that leaks out into the surrounding soil can fuel aerobic ammonia and nitrite oxidation. Subsequent diffusion of nitrate to anoxic zones in soil fuels nitrogen-transforming processes such as dissimilatory nitrate reduction to ammonium, nitrous oxide and dinitrogen gas. d) Rice paddies are flooded agricultural fields, which are fertilized

1131 with nitrogen-containing compounds such as urea to grow rice ${ }^{155}$. Urea hydrolysis and nitrogen

1132 fixation generate ammonia, which is oxidized to nitrate in oxic soils surrounding the rice-plant 1133 roots. Subsequent diffusion of nitrate to the underlying anoxic soil fuels processes, such as 1134 denitrification, anaerobic ammonium oxidation (anammox) and the oxidation of methane 1135 produced by methanogenesis.

\section{Key points}

- Nitrogen is an essential component of all living organisms and the main nutrient limiting life on our planet. Its availability depends on diverse nitrogen transforming reactions that are carried out by microorganisms.

- Nitrogen-transforming microorganisms are metabolically versatile rendering their classification as mere 'nitrifiers' or 'denitrifiers' etc. inadequate.

- The classical nitrogen cycle consisting of distinct processes that follow each other in an orderly fashion does not exist. In nature, microorganisms form complex networks that link nitrogen-transforming reactions.

- Microbial nitrogen-transforming networks both attenuate and exacerbate humaninduced global change. They produce and consume the powerful greenhouse gas nitrous oxide; lead to eutrophication of aquatic systems and at the same time remove nitrogen from wastewater.

- There are still many undiscovered nitrogen-transforming reactions that are thermodynamically feasible. The microorganisms catalyzing these reactions and the involved biochemical pathways are waiting to be discovered. 
Glossary Terms

1156

1157 Reductant

1158 The electron-donating compound in a redox reaction.

1159

\section{Oxygenic phototroph}

1161 Oxygenic phototrophs obtain energy from light and use water as the electron donor, forming 1162 molecular oxygen and sugar as products.

1163

\section{Bacteriocytes}

1165 Special cells in animals that contain endosymbiotic bacteria.

\section{Thaumarchaeota}

1168 The phylum Thaumarchaeaota contains the ammonia-oxidizing archaea.

1169

\section{Acidophile}

1171 An organism that grows in acidic environments $(<\mathrm{pH} 6)$.

1173 Methanotroph

1174 An organism that oxidises methane to conserve energy.

1175

1176 NC10

1177 A candidate bacterial phylum, named after Nullarbor Caves in Australia, which contains

1178 Candidatus Methylomirabilis oxyfera, which is the first organism discovered that performs 1179 methane oxidation coupled to oxygenic denitrification.

\section{Endergonic}

1182 A reaction that requires energy input.

\section{Verrucomicrobia}

1185 A bacterial phylum with only a few described species, some of which appear to be important in 1186 the methane cycle. 


\section{Anoxygenic phototroph}

1189 These microorganisms obtain energy from light and use compounds such as hydrogen sulfide instead of water as electron donor and thus do not produce molecular oxygen.

\section{Eutrophication}

1193 The excessive growth of algae or cyanobacteria due to increased input of nutrients.

\section{Proton motive force}

1196 Proton dislocation creates a difference of charge and $\mathrm{pH}$ between two sides of a cell membrane and thereby generates an electrochemical potential, which is used for energy conservation.

\section{Primary nitrite maxima}

1200 The peak in nitrite concentrations at the base of the euphotic zone.

\section{Nitric oxide dismutation}

1203 Two molecules of nitric oxide are disproportionated into one molecule of molecular oxygen and one molecule of dinitrogen gas.

1205

\section{Comproportionation}

1207 A chemical reaction in which two reactants containing the same element with a different oxidation state react to create a product with a single oxidation state.

\section{Anammoxosome}

A bacterial organelle found in anammox bacteria, which is the only known prokaryotic membrane-bound structure that is equally divided into daughter cells upon cell division.

\section{Exergonic}

A reaction that results in the release of free energy.

\section{Disproportionation}

1218 A chemical reaction in which a reactant is split into two species containing the same element

1219 with different oxidation states, one more oxidized and the other more reduced than the reactant.

\section{Anaerobic sludge digesters}


1223 Bioreactors in which excess microbial biomass (sludge) produced during wastewater treatment

1224 is anaerobically converted to carbon dioxide, methane, ammonium and reduced sulfur 1225 compounds.

1226

1227

1228

1229

1230

1231

1232

1233

1234

1235

1236

1237

1238

1239

1240

1241

1242

1243

1244

1245

1246

1247

1248

\section{Subject categories}

Biological sciences / Microbiology / Biogeochemistry / Element cycles

[URI /631/326/47/4112]

Biological sciences / Ecology / Microbial ecology

[URI /631/158/855]

Biological sciences / Microbiology / Environmental microbiology

[URI /631/326/171]

Biological sciences / Biochemistry / Enzymes / Oxidoreductases

[URI /631/45/607/1168]

Biological sciences / Ecology / Ecological networks

[URI /631/158/2463]

\section{ToC blurb}

Nitrogen-transforming microorganisms shape global biogeochemical nutrient cycles. In this Review, Kuypers, Marchant and Kartal explore the vast diversity of these microorganisms and their enzymes, highlighting novel pathways, and discuss how nitrogen-transforming microorganisms form complex nitrogen-cycling networks in different environments. 
Fig. 1
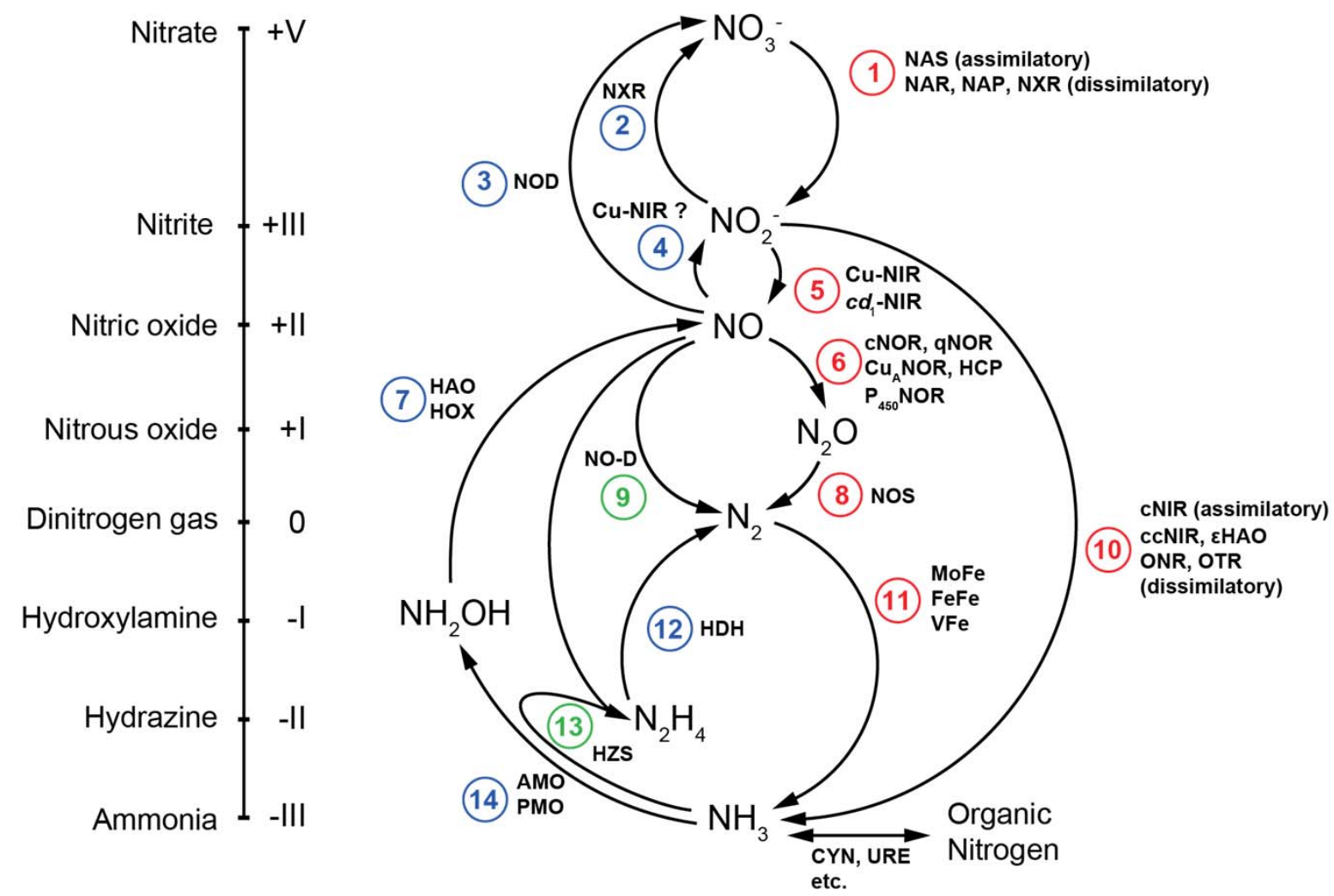

(1) $\mathrm{NO}_{3}^{-}+2 \mathrm{e}^{-}+2 \mathrm{H}^{+} \rightarrow \mathrm{NO}_{2}^{-}+\mathrm{H}_{2} \mathrm{O}$

(2) $\mathrm{NO}_{2}^{-}+\mathrm{H}_{2} \mathrm{O} \rightarrow \mathrm{NO}_{3}^{-}+2 \mathrm{e}^{-}+2 \mathrm{H}^{+}$

(3) $\mathrm{NO}+2 \mathrm{H}_{2} \mathrm{O} \rightarrow \mathrm{NO}_{3}^{-}+3 \mathrm{e}^{-}+4 \mathrm{H}^{+}$

(4) $\mathrm{NO}+\mathrm{H}_{2} \mathrm{O} \rightarrow \mathrm{NO}_{2}^{-}+\mathrm{e}^{-}+2 \mathrm{H}^{+}$

(5) $\mathrm{NO}_{2}^{-}+\mathrm{e}^{-}+2 \mathrm{H}^{+} \rightarrow \mathrm{NO}+\mathrm{H}_{2} \mathrm{O}$

(6) $\mathrm{NO}+2 \mathrm{e}^{-}+2 \mathrm{H}^{+} \rightarrow \mathrm{N}_{2} \mathrm{O}+\mathrm{H}_{2} \mathrm{O}$

(7) $\mathrm{NH}_{2} \mathrm{OH} \rightarrow \mathrm{NO}+3 \mathrm{e}^{-}+3 \mathrm{H}^{+}$

(8) $\mathrm{N}_{2} \mathrm{O}+2 \mathrm{e}^{-}+2 \mathrm{H}^{+} \rightarrow \mathrm{N}_{2}+\mathrm{H}_{2} \mathrm{O}$

(9) $2 \mathrm{NO} \rightarrow \mathrm{N}_{2}+\mathrm{O}_{2}$

(10) $\mathrm{NO}_{2}^{-}+6 \mathrm{e}^{-}+8 \mathrm{H}^{+} \rightarrow \mathrm{NH}_{4}^{+}+2 \mathrm{H}_{2} \mathrm{O}$

(11) $\mathrm{N}_{2}+8 \mathrm{e}^{-}+8 \mathrm{H}^{+}+16 \mathrm{ATP} \rightarrow 2 \mathrm{NH}_{3}+\mathrm{H}_{2}+16 \mathrm{ADP}+16 \mathrm{P}_{\mathrm{i}}$

(12) $\mathrm{N}_{2} \mathrm{H}_{4} \rightarrow \mathrm{N}_{2}+4 \mathrm{e}^{-}+4 \mathrm{H}^{+}$

(13) $\mathrm{NO}+\mathrm{NH}_{4}^{+}+3 \mathrm{e}^{-}+2 \mathrm{H}^{+} \rightarrow \mathrm{N}_{2} \mathrm{H}_{4}+\mathrm{H}_{2} \mathrm{O}$

(14) $\mathrm{NH}_{4}^{+}+\mathrm{O}_{2}+2 \mathrm{e}^{-}+\mathrm{H}^{+} \rightarrow \mathrm{NH}_{2} \mathrm{OH}+\mathrm{H}_{2} \mathrm{O}$ 
Fig. 2

a.

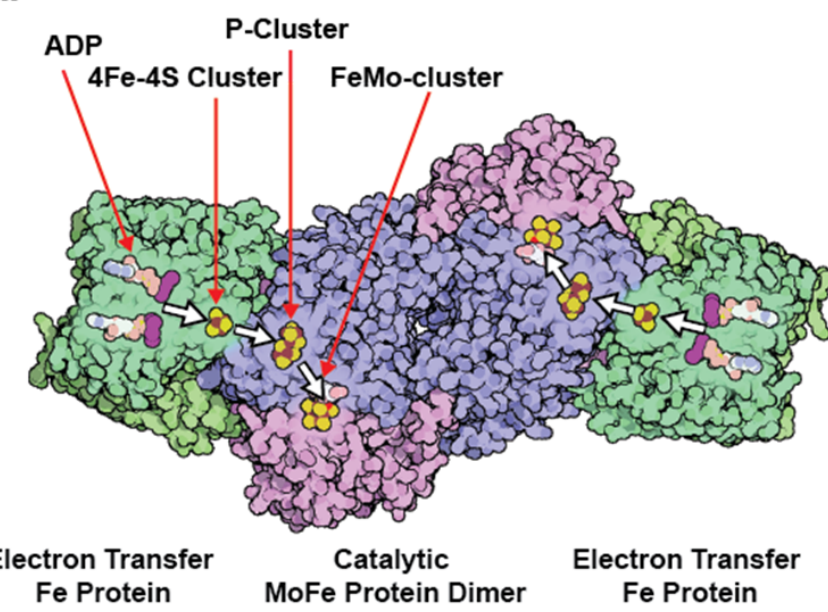

c.

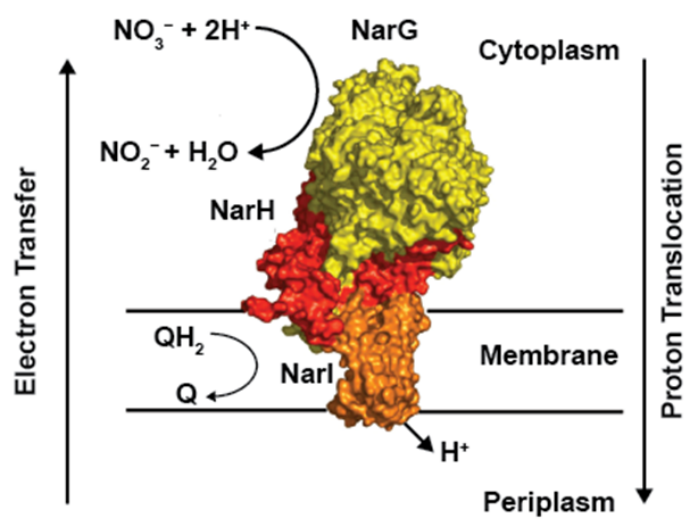

b.

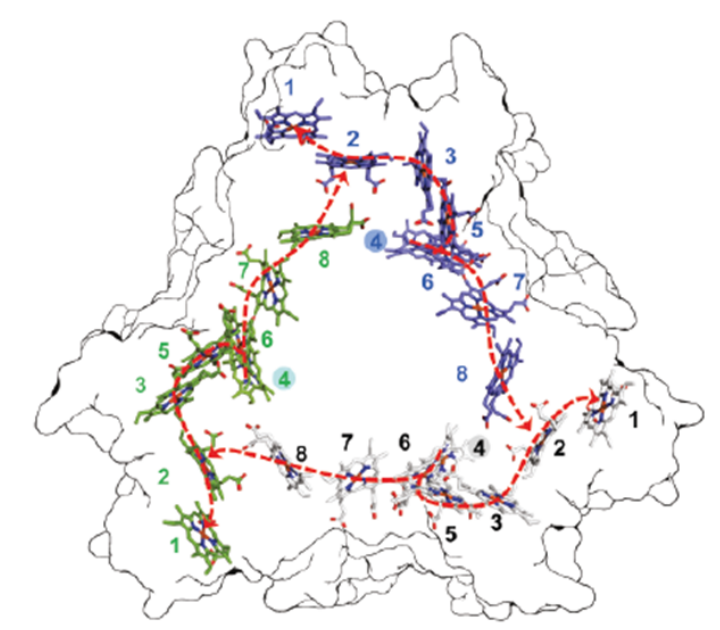

d.

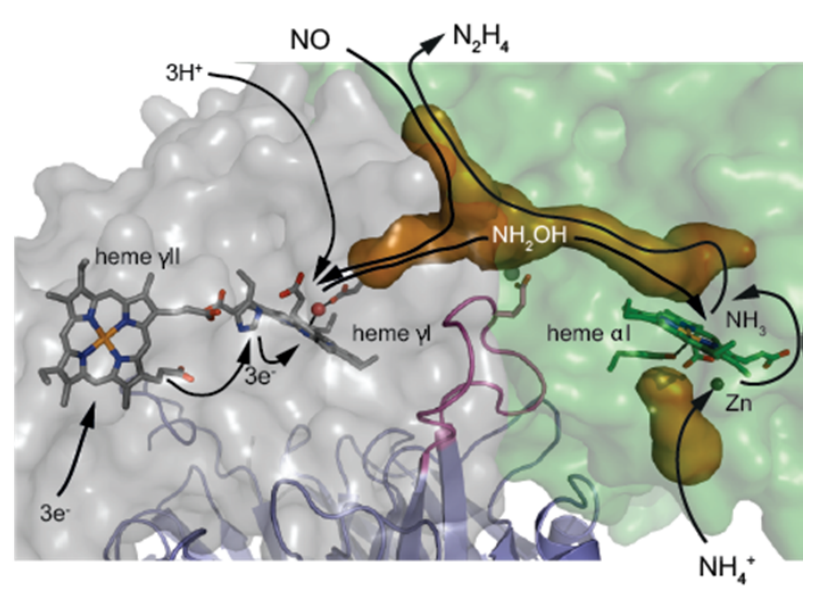


Fig. 3

a.

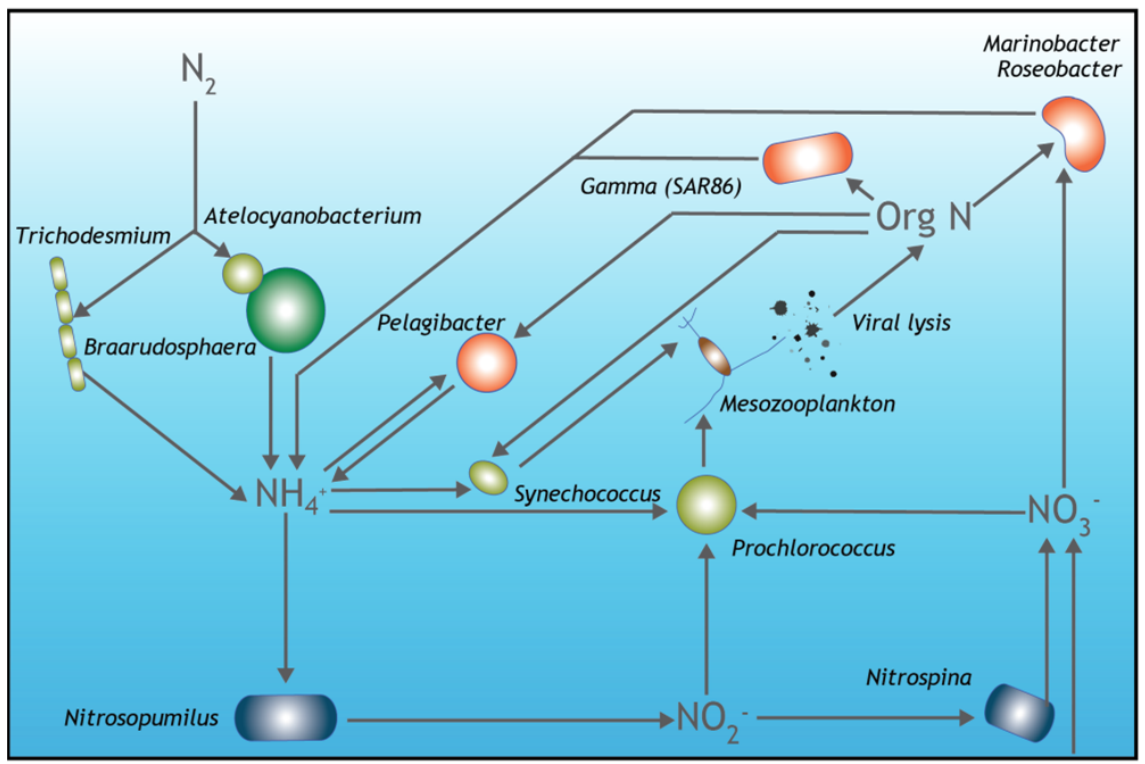

c.

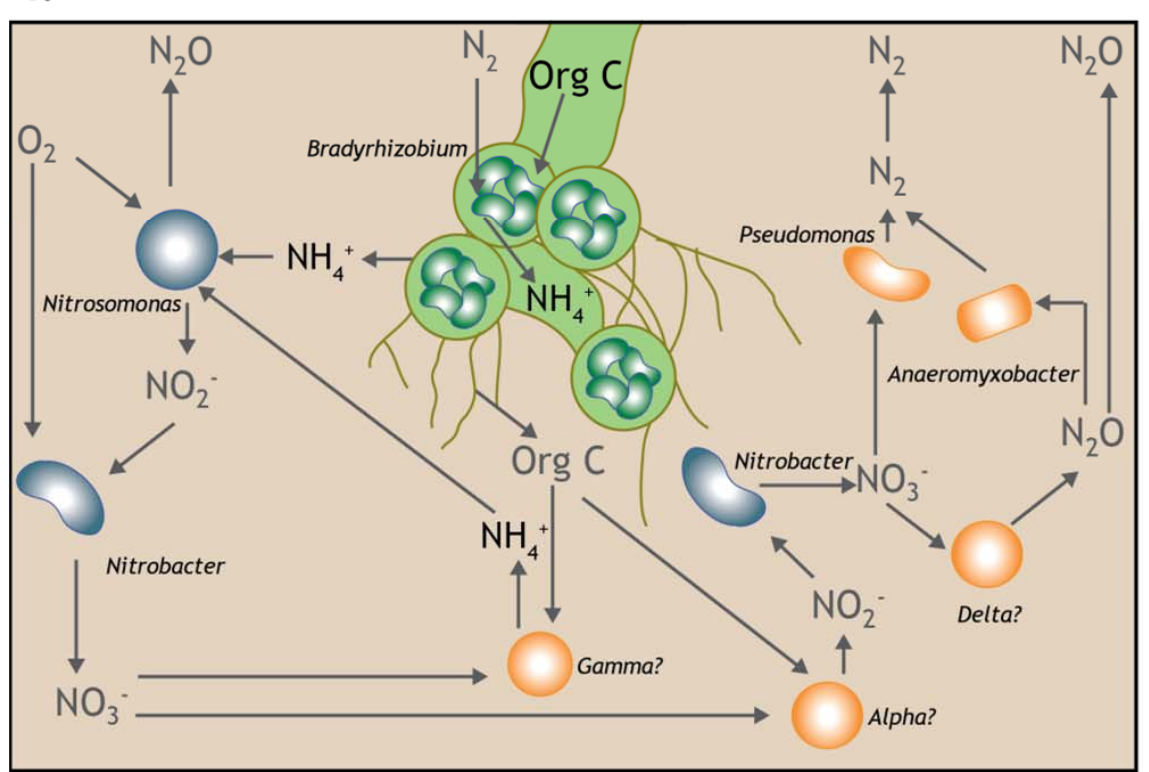

b.

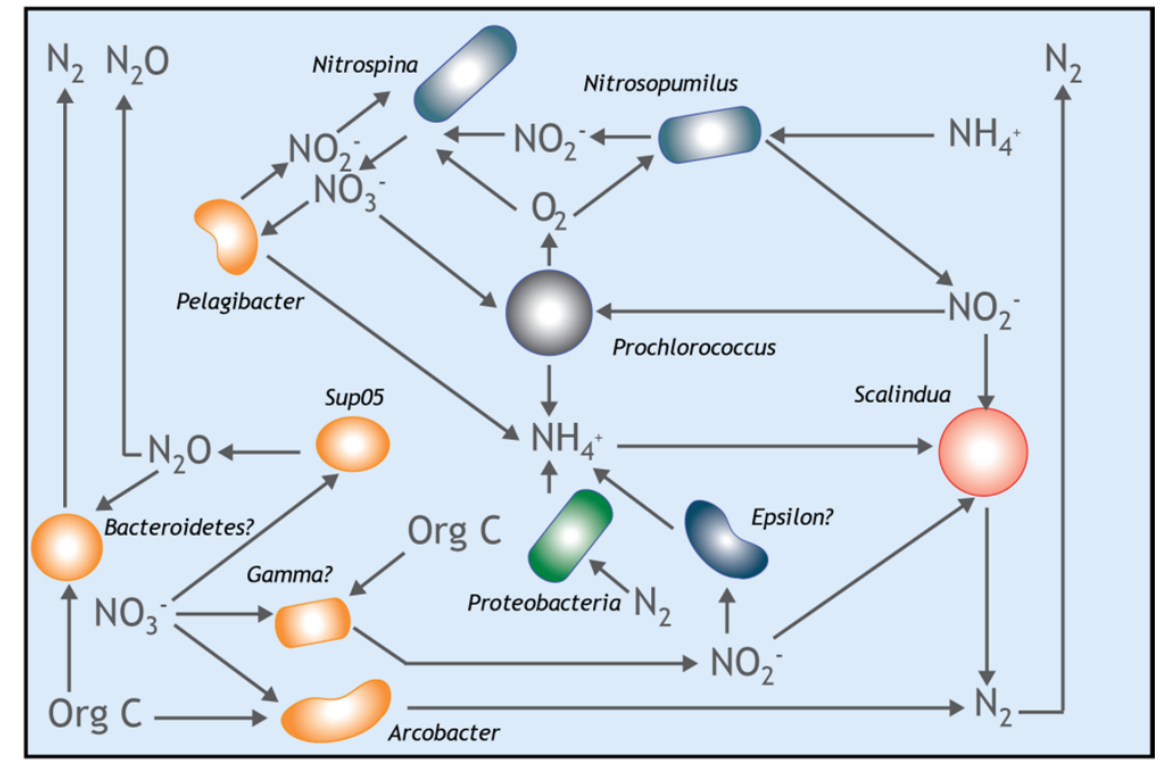

d.

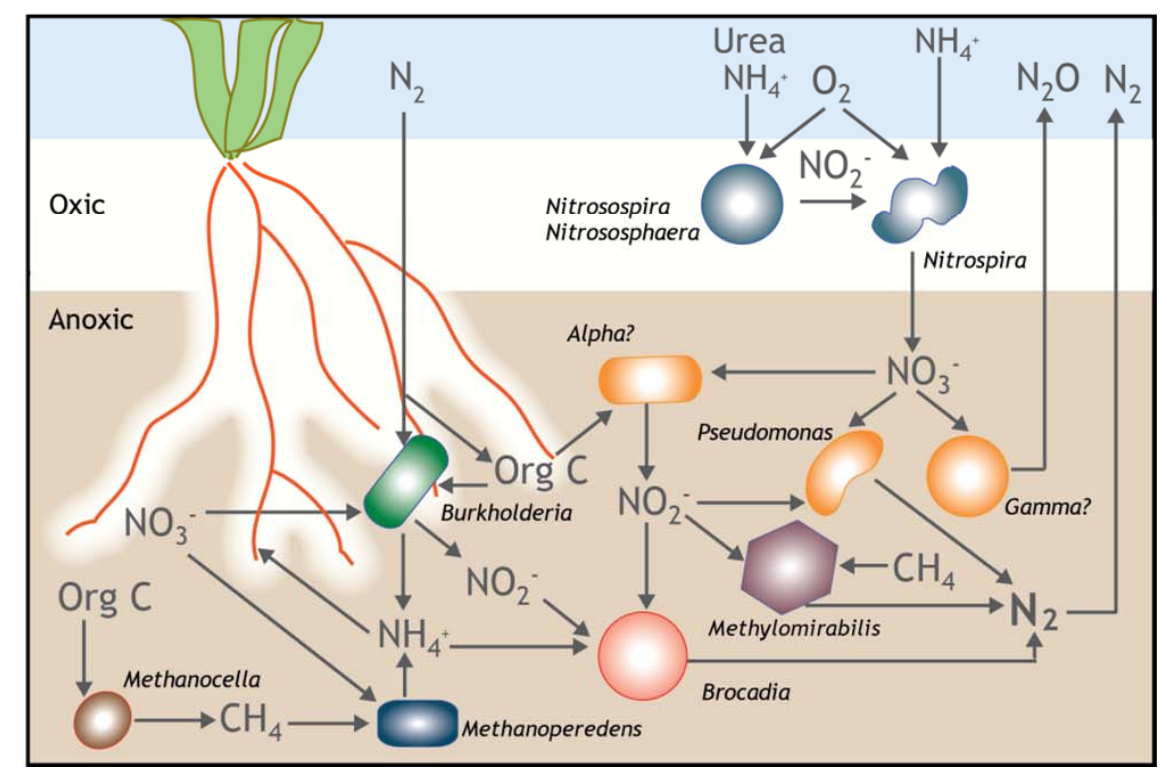




\section{Text Box 1}
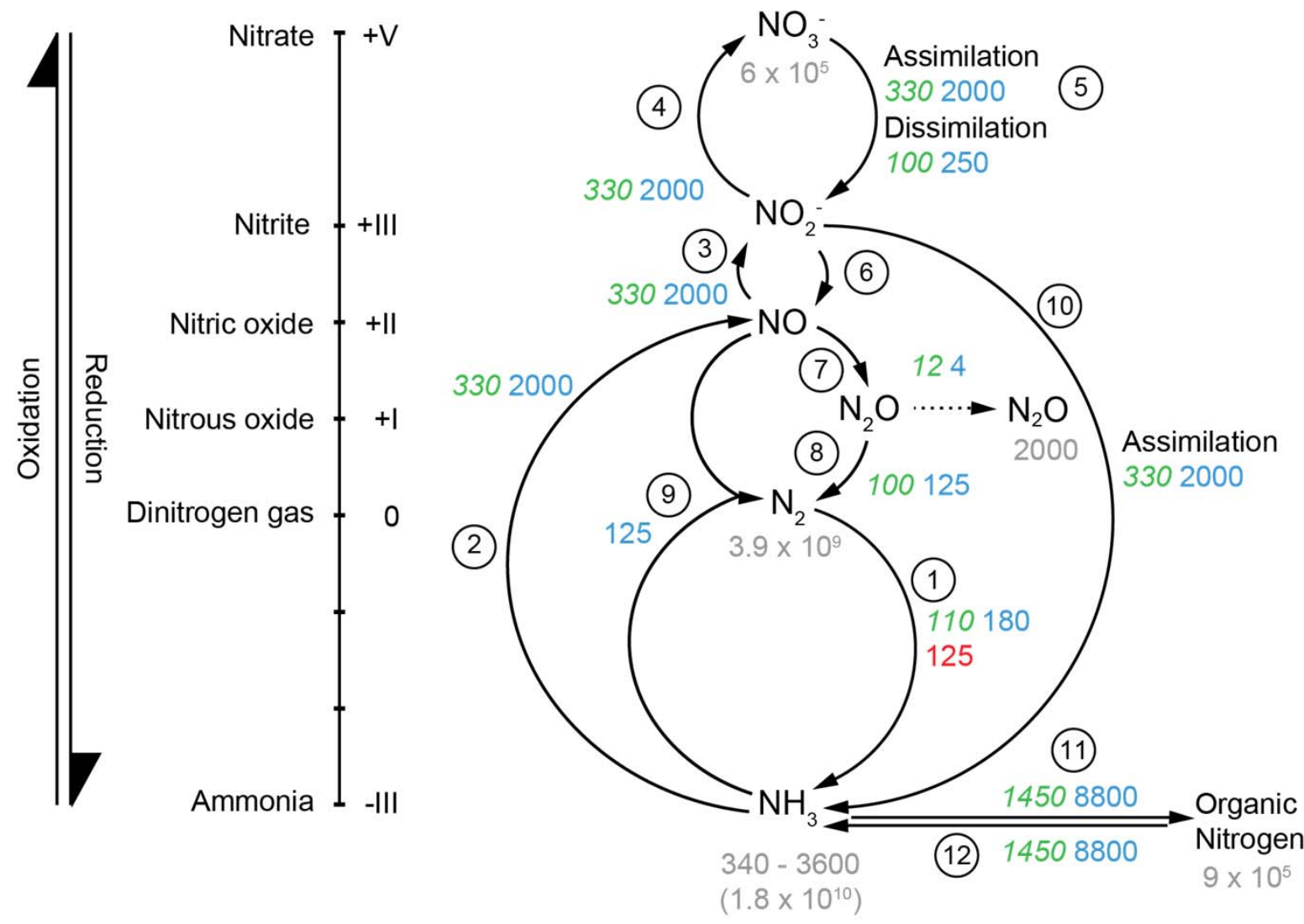

\section{Nitrogen-transforming processes}

Nitrogen fixation (1)

Nitrification (2) (3) (4)

Denitrification (5) (6) (7) (8)

Anammox (6) (9)

Assimilation (5) (10) and (11)

Ammonification (12) 


\section{Text Box 2}

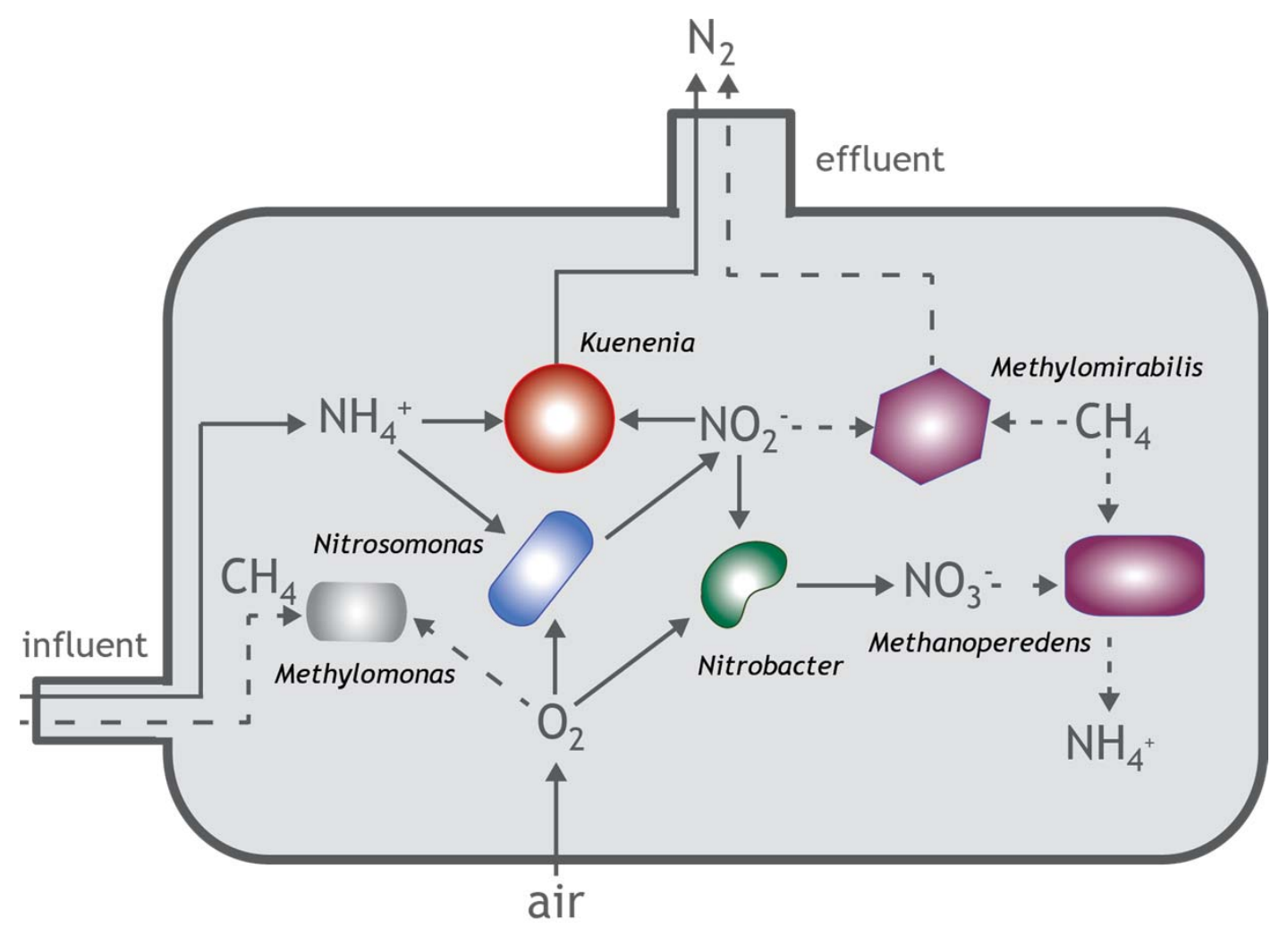

